Article

\title{
Virtual Detection of Mechanically Induced Short Circuits in a Cylindrical Lithium-Ion Battery Cell Based on Finite Element Simulation
}

\author{
Klemens Jantscher ${ }^{1, *}$, Christoph Breitfuß ${ }^{1}$, Martin Miklau ${ }^{1}$, Khaled Ismail ${ }^{1}$ and Peter Dobusch ${ }^{2}$ \\ 1 Virtual Vehicle Research GmbH, Inffeldgasse 21A, 8010 Graz, Austria; christoph.breitfuss@v2c2.at (C.B.); \\ martin.miklau@v2c2.at (M.M.); khaled.ismail@v2c2.at (K.I.) \\ 2 Kreisel Electric GmbH \& Co. KG, Kreiselstraße 1, 4261 Rainbach im Mühlkreis, Austria; \\ peter.dobusch@kreiselelectric.com \\ * Correspondence: klemens.jantscher@v2c2.at
}

Citation: Jantscher, K.; Breitfuß, C.; Miklau, M.; Ismail, K.; Dobusch, P. Virtual Detection of Mechanically Induced Short Circuits in a Cylindrical Lithium-Ion Battery Cell Based on Finite Element Simulation. Batteries 2021, 7, 79. https:// doi.org/10.3390/batteries7040079

Academic Editor: Matthieu Dubarry

Received: 22 August 2021

Accepted: 16 November 2021

Published: 17 November 2021

Publisher's Note: MDPI stays neutral with regard to jurisdictional claims in published maps and institutional affiliations.

Copyright: (C) 2021 by the authors Licensee MDPI, Basel, Switzerland. This article is an open access article distributed under the terms and conditions of the Creative Commons Attribution (CC BY) license (https:// creativecommons.org/licenses/by/ $4.0 /)$.

\begin{abstract}
Lithium-ion batteries (LIBs) are commonly used in today's electric vehicles. Studying their behaviour under mechanical loading, including short circuits, is vital for vehicle safety. This paper covers three major topics, (1) a general literature review for the state-of-the-art of LIBs, (2) physical cell tests for model validation are performed, wherein the occurrence of short circuits is detected and (3) creating a finite element model (FEM) of an 18650 cylindrical LIB using the most recent testing and simulation techniques. A variety of short-circuit criteria based on stresses, strains and geometric parameters have been implemented in the simulation and compared to the test results. It will be demonstrated that a combination of two geometric criteria, in the radial and axial directions of the cell, is best suited for virtual short-circuit detection in the simulation. Finally, the short-circuit criteria are implemented in a post-processing tool that allows fast short-circuit analysis of cells of different loadings. In the future, this method of short-circuit detection will be used to analyse an assembly of several battery cells such as, for instance, an automotive or maritime battery pack. Furthermore, the developed method enables mechanical integration with respect to crash safety in vehicles.
\end{abstract}

Keywords: lithium-ion battery; plastic deformation; short circuit; vehicle safety; finite element simulation

\section{Introduction}

Since the development of the first LIBs in the 20th century the technology has passed through different milestones, starting with primary batteries and ending with the recent state (secondary batteries) [1]. In 1991, commercial use of this technology began and, since then, remarkable progress regarding materials [2] and cell design has been made. The advantages of this technology caused its widespread usage in different fields, such as in electronics, laptops and electric vehicles. Especially in the automotive sector, the technology faces great challenges, such as capacity, weight, charging speed and crash safety.

Electric vehicles have become an important part of today's automotive industry. With the growing use of this technology, safety concerns need to be addressed. lithium-ion battery systems are at the center of these concerns, as they can cause fires when damaged. For manufacturers to assess their safety measures during their development process, precise simulation models can be very helpful. Especially, the virtual prediction of short circuits is needed, since short circuits are the main cause of battery-induced fire. This document gives an overview of the literature on lithium-ion battery mechanical testing, finite element modelling and short-circuit mechanisms, including their detection. This is followed by the description of the simulation model design. A state-of-the-art finite element model of a battery is created and validated using data collected in mechanical tests performed on several 18650 LIBs. The necessary quantities measured during these tests are force over displacement and the occurrence of a short circuit, which is obtained by an open circuit 
voltage $(\mathrm{OCV})$ measurement. In addition, testing videos are used to compare deformation behaviour. Two finite element solvers have been used to create a universally applicable model. Continuing, the main part of this work is the research on short circuit criteria, to realize virtual short circuit detection within the simulation model. Several stress- and strain-based criteria as well as geometric criteria are investigated. Finally, the results of these investigations are shown and discussed.

\subsection{State of the Art}

The following literature study gives an overview of the state-of-the-art of mechanical battery testing, finite element (FE) simulation of lithium-ion batteries for crash purposes and virtual internal short-circuit prediction in battery cells.

\subsubsection{Battery Cell Mechanical Deformation, Testing and FE Simulation}

The mechanical deformation of battery cells and packs is a very important aspect of battery safety. In designing a robust battery cell, one of the key elements is understanding its limits of mechanical integrity, itself necessary for electric integrity in any vehicle crash to protect against an electric short circuit (SC). Such a short circuit can cause the battery to produce large amounts of heat and to even cause a fire. Consequently, in the last decade, many research groups have investigated the mechanical properties and the crash behaviour of Li-ion battery cells and packs in a sophisticated way. In the following, the most common standard mechanical tests used in the evaluation of the mechanical properties, as well as the crash behaviour of the battery cells, are presented (Figure 1). A summary of the literature focusing on the correlation between the experimental tests and numerical simulations of the battery cell under various loading scenarios is attached in the Appendix A (Table A1). Figure 1 illustrates the four mechanical testing scenarios most commonly performed on 18650 lithium-ion cells.

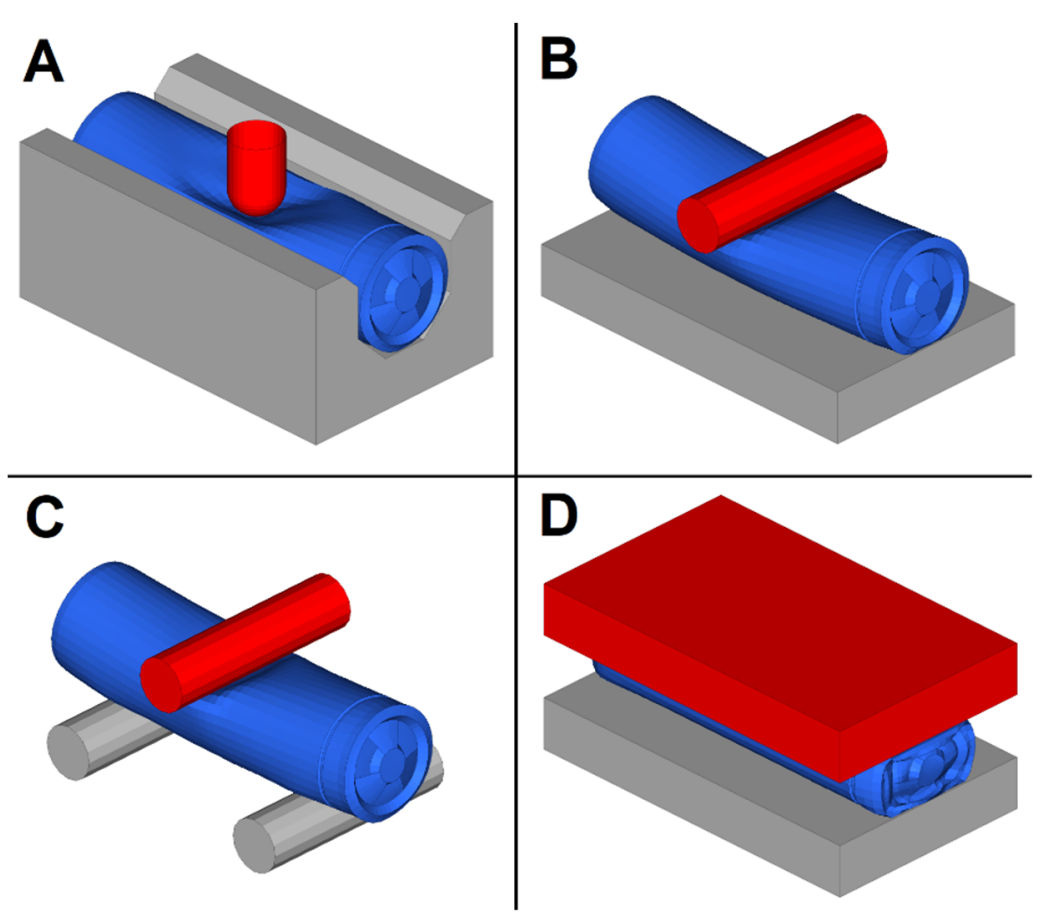

Figure 1. (A) Indentation by a hemispherical punch; (B) lateral indentation by a cylindrical rod; (C) three-point bending and (D) compression between two flat plates.

In the study described in this publication, three of these mechanical tests are performed: lateral indentation by a cylindrical rod, compression between two flat plates and three-point bending. These three load cases examine the batteries in a radial direction. Since the simulation model is supposed to work for mechanical abuse in every direction, a 
fourth test is necessitated, which is axial compression between two flat plates. This test is less common but can be found in several of the publications mentioned in Table A1.

Several approaches are commonly used for the simulation of the jellyroll part of the lithium-ion batteries. They are depicted in Figure 2 and described in the following:

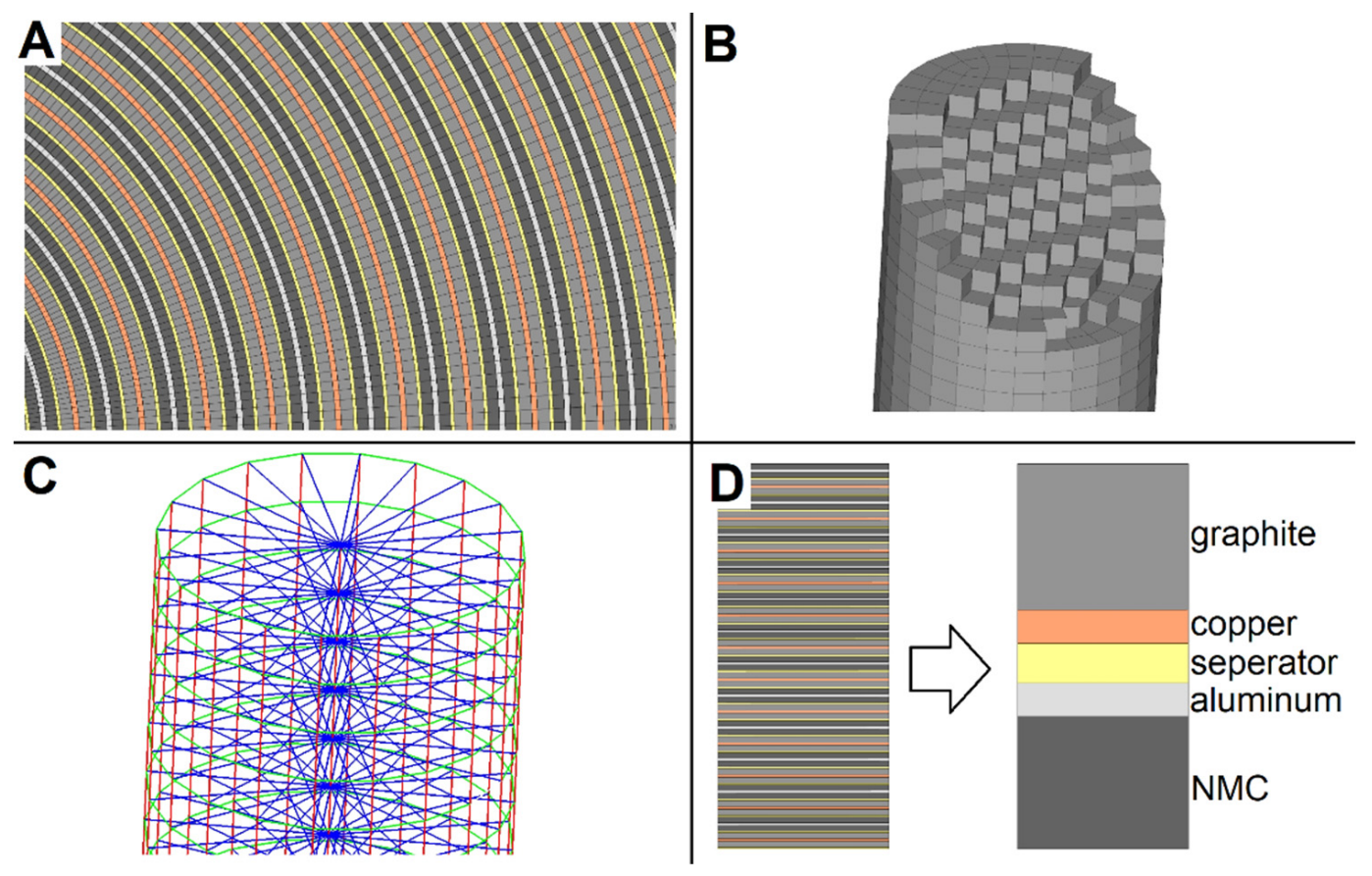

Figure 2. (A) meso-mechanical model, (B) representative volume element method, (C) beam method, (D) scaled representative sandwich.

In a meso-mechanical model, all layers of the jellyroll are simulated individually. Their properties are homogenous. This type of model has high calculation times [3].

The representative volume element (RVE) method is a macroscopic approach. It uses sum properties for the jellyroll, which is modelled with solid elements. Due to this simplification, this model can be calculated very fast. This method is generally accepted and is also used herein [4].

In the beam method, three kinds of beam represent the jellyroll and the hardcase. Axial, radial and circumferential beams with different mechanical properties deliver stiffness in their directions. A surrounding null-shell is needed for contact reasons. This model has short calculation times [5].

The scaled representative sandwich (SRS) is a hybrid method between meso- and macro-mechanic modelling. All layers of each type (separator, copper, aluminium, anodeand cathode-active material) are merged to one single layer, with cumulated thickness. This method is faster than the meso-mechanical approach, but it has some disadvantages. The location of the short circuit is not exact and there is a non-realistic stress distribution [6].

In general, the quality of a simulation model is limited by the data it is based upon. Simplifications, to a certain degree, are always necessary in its creation, which cause inaccuracies in the results.

\subsubsection{Virtual Internal Short Circuit Prediction}

The accurate prediction of an internal short-circuit event due to mechanically abusive conditions is one of the major research interests in the field of battery technology, because, once an internal short circuit begins, it may lead to thermal runaway. Due to the criticality of such an event, many researchers have focused their research on the investigation of short-circuit mechanisms and applied different methods to predicting short circuits. A summary of the methods found in the literature is attached in the Appendix A (Table A2). 
Basically, a short circuit is assumed to be an instantaneous discrete process, i.e., at $t \geq t_{\text {short }}$ there appears an electrically conductive path between the two layers undergoing the short, as illustrated in the example in Figure 3 [7].

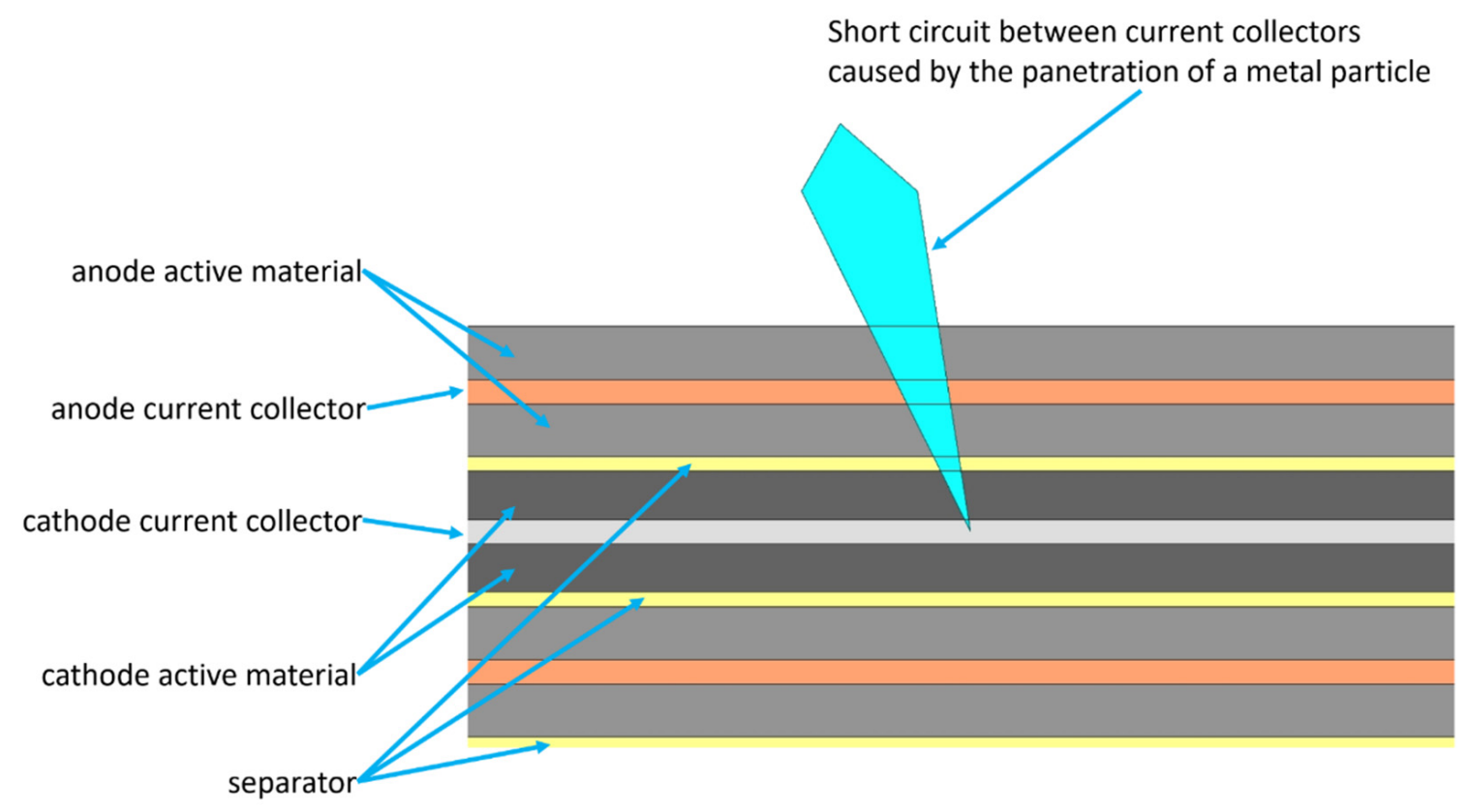

Figure 3. Diagrammatic representation of an internal short-circuit.

Figure 3 shows the cell model and its components. A short circuit is created by a penetrating particle, marked green, connecting copper current collector and cathode's active material. Four different scenarios of a short circuit may occur in the lithium-ion cells [7-9]:

The first scenario is a short between the current collectors (copper and aluminium) which causes a high turnover of power due to low resistance $(<10 \mathrm{~m} \Omega)$. Due to the good thermal conductivity of copper, the cell is heated homogeneously and the thermal runaway usually does not occur.

The second scenario is a short circuit between the copper current collector and the cathode active material which rarely occurs. The process is controlled by the high resistance of this combination $(>100 \mathrm{~m} \Omega)$. The degradation of the cathode material happens at temperatures lower than needed to start the chemical decomposition process.

The third scenario is a short circuit between anode active material and aluminium current collector which is the worst-case scenario. The resistance of this combination is low $(\sim 100 \mathrm{~m} \Omega)$ but the thermal conductivity of aluminium is not as high as it is for copper. This leads to localized heating of the cell, which leads to decomposition of the anode material, which creates further heat.

The fourth scenario is a short circuit between the active materials of both electrodes, which is the most likely to occur. In this case, resistance is high because of the cathode material $(>100 \mathrm{~m} \Omega)$.

In the literature, several methods for virtual short-circuit prediction were found [3-5,10-13]:

- Mohr-Coulomb failure criterion

- force drop criterion

- criterion based on unified strength theory

- criterion based on von Mises equivalent strain

- criterion based on volumetric strain

- criterion based on main normal strain

- criterion based on maximum principal stress

- criterion based on von Mises equivalent stress 
- criterion based on deformation in length and diameter

The Mohr-Coulomb fracture criterion, which takes into account shear, compressive and normal stresses, and is used to predict the breaking of the jellyroll and the short circuit that coincides with it [10].

The force drop criterion uses the fact that, under mechanical loading, a drop in force measurement coincides with a short circuit $[3,4]$.

The unified strength theory criterion

$$
\sigma_{\text {Unified }}^{e q}=\left\{\begin{array}{c}
\sigma_{1}-\frac{\alpha}{1+b} \cdot\left(b \cdot \sigma_{2}+\sigma_{3}\right), \quad \sigma_{2} \leq \frac{\sigma_{1}+\alpha \cdot \sigma_{3}}{1+\alpha} \\
\frac{1}{1+b} \cdot\left(\sigma_{1}+b \cdot \sigma_{2}\right)-\alpha \cdot \sigma_{3}, \quad \sigma_{2} \geq \frac{\sigma_{1}+\alpha \cdot \sigma_{3}}{1+\alpha}
\end{array}\right.
$$

is based on the principal stresses $\left(\sigma_{1}, \sigma_{2}, \sigma_{3}\right)$, the ratio between tension and compression $(\alpha)$ and a weighing factor $(b)$, which, corresponding to twin shear theory, is set as one [13].

The other criteria are explained in detail in Section 4, where they are applied.

Some of these criteria are based on physical data. Such criteria can be used with meso-mechanical models. With these models, it is also possible to determine the type of short circuit. Several of these methods are investigated in this publication.

This work puts the focus on cylindrical LIBs. It has to be noted, at this point, that the described methods are also applicable for other cell designs, such as pouch cells or prismatic cells [14-16].

\section{Mechanical Abuse Testing}

For the creation of a reliable simulation model of the 18650 lithium-ion battery, data from real-life tests is needed. This section describes the experimental setups used and the data gained therefrom on the batteries' mechanical behaviours.

\subsection{Cell Case Testing}

In the following, only the load-case radial crush impactor, as a representative of all cases, is discussed. The load-case radial crush impactor will serve as a continuing example for all load cases used throughout this paper. Results and discussions of the other load cases are shown in Appendix B.

Quasi-static testing of empty cell cases was done with three different test set-ups described in Table 1.

Table 1. Three mechanical abuse tests for empty-type 18650 battery cell cases.

\begin{tabular}{ccccc}
\hline & Amount & Speed $/ \mathbf{m m} / \mathbf{m i n}$ & Abort Criterion & Boundary Condition \\
\hline radial crush & 3 & 5 & $50 \%$ deformation & flat plate \\
\hline radial crush & 3 & 1 & $50 \%$ deformation & flat plate \\
\hline radial crush impactor & 3 & 1 & $50 \%$ deformation & cylindrical impactor \\
\hline
\end{tabular}

The testbench used to perform all mechanical tests is shown in Figure 4. It is a custom-built hydraulic press with a load cell that can withstand forces of up to $100 \mathrm{kN}$. The maximum force measurement is at $40 \mathrm{kN}$, restricted by the measurement amplifier. 


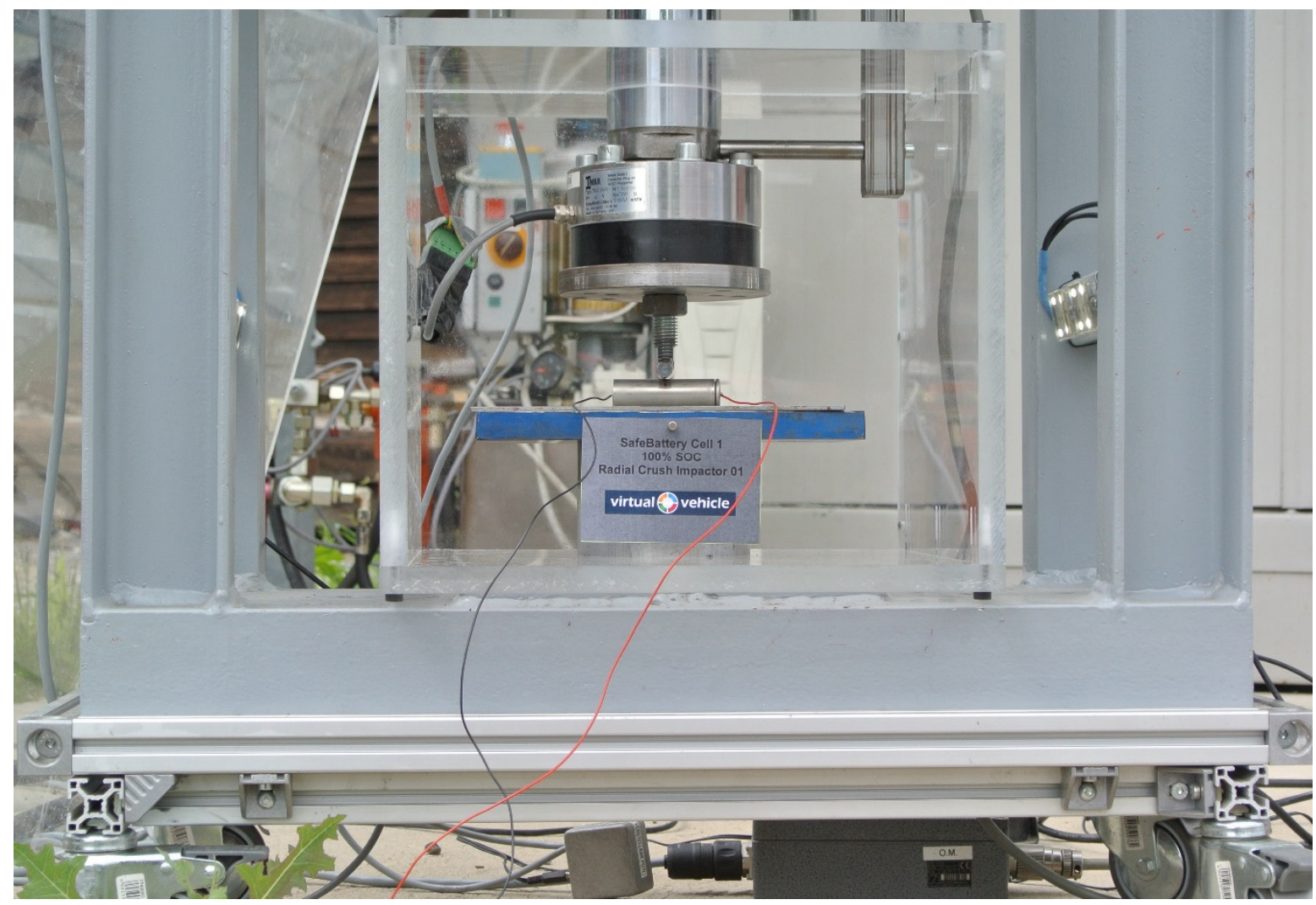

Figure 4. Hydraulic test bench.

The force-displacement curves (Figure 5A) show that there is good repeatability for the test results. The maximum deformation for the validation of the simulation model (validation limit) can be estimated at approx. $5.6 \mathrm{~mm}$, based on occurring short circuits in cell tests (Figure 6). Figure 5B shows the deformed specimen of test 01.

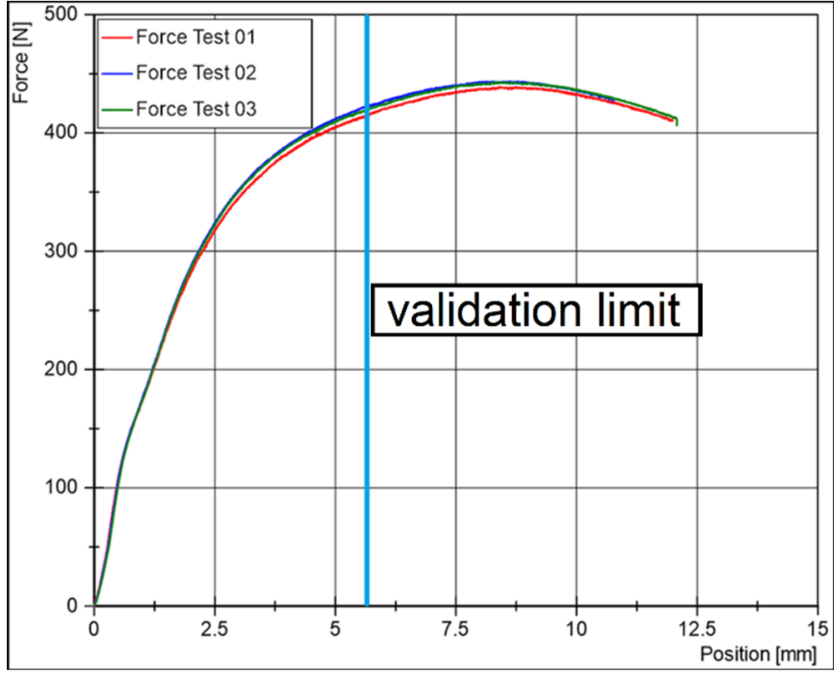

A

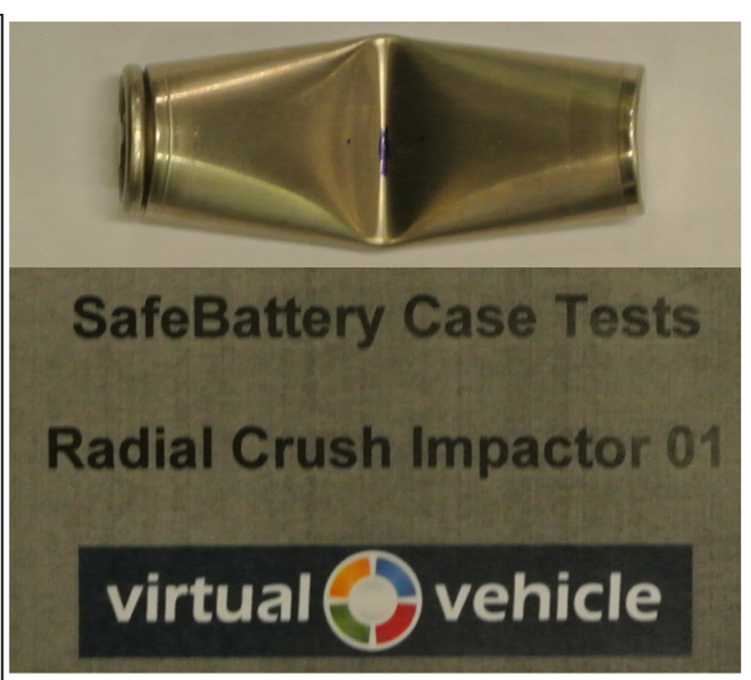

B

Figure 5. Results of the cell-case test for the load-case radial crush impactor (A) and cell-case specimen after testing (B). 


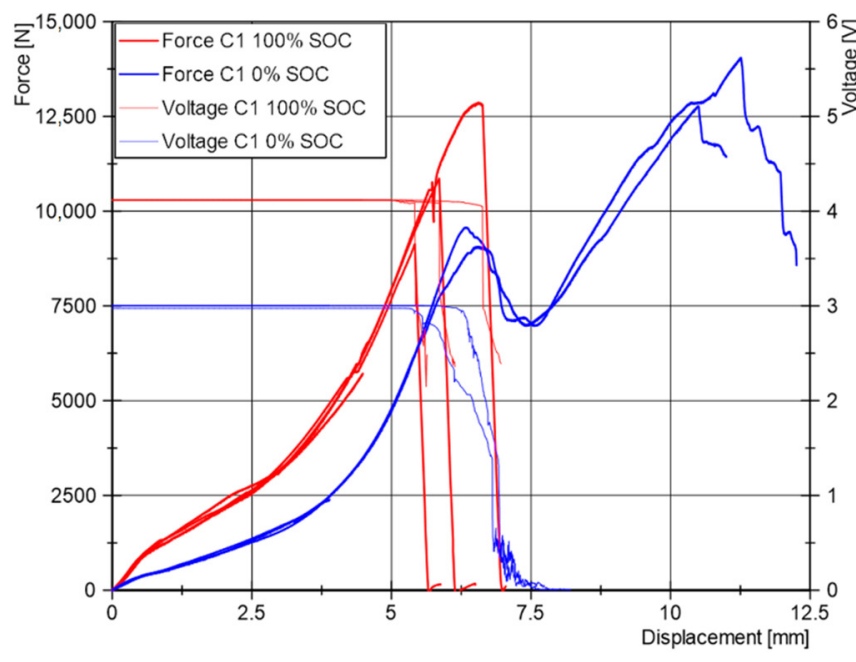

A

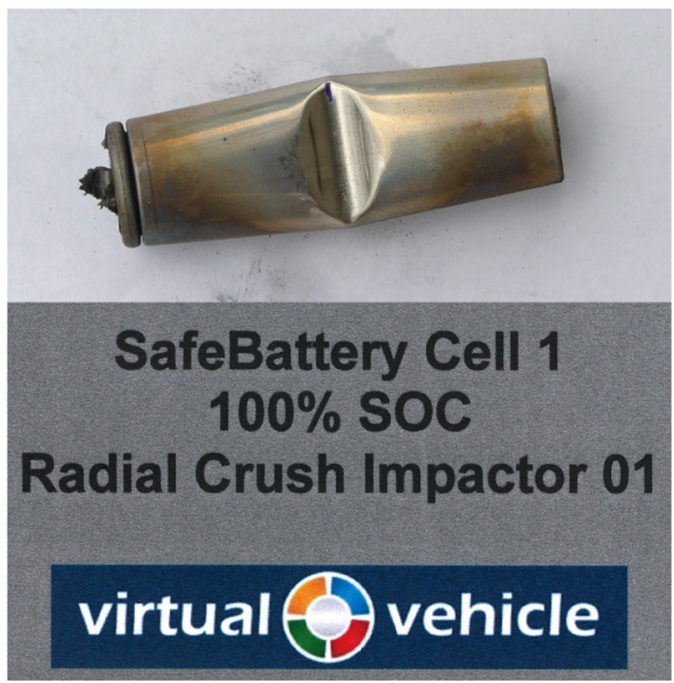

B

Figure 6. Radial crush impactor C1 (SOC comparison) force over displacement (A) and cell specimen after testing (B).

\subsection{Cell Testing}

The tests of the whole cell (including the jelly roll) were conducted with four different test setups. Cells with maximal and minimal states of charge (SOC) were used. Table 2 shows the realized test matrix.

Table 2. Four mechanical abuse tests for type 18650 lithium-ion battery cells.

\begin{tabular}{|c|c|c|c|c|c|c|}
\hline & Amount & $\mathrm{SOC} / \%$ & $\begin{array}{c}\text { Speed } \\
\mathrm{mm} / \mathrm{min}\end{array}$ & Abort Criterion & Boundary Condition & Test Principle \\
\hline \multirow{2}{*}{ axial crush } & 4 & 100 & 5 & short circuit & \multirow{2}{*}{ flat plate } & \\
\hline & 2 & 0 & 5 & $50 \%$ deformation & & \\
\hline \multirow{2}{*}{ radial crush } & 4 & 100 & 1 & short circuit & \multirow{2}{*}{ flat plate } & \\
\hline & 2 & 0 & 1 & $50 \%$ deformation & & \\
\hline \multirow{2}{*}{$\begin{array}{l}\text { radial crush } \\
\text { indentation }\end{array}$} & 4 & 100 & 1 & short circuit & \multirow{2}{*}{ cylindrical impactor } & \\
\hline & 2 & 0 & 1 & $50 \%$ deformation & & \\
\hline \multirow{2}{*}{ 3-point bending } & 4 & 100 & 1 & short circuit & reproducing & \\
\hline & 2 & 0 & 1 & force drop & installation situation & \\
\hline
\end{tabular}

For axial crush, the specimens are deformed mainly in axial direction. For radial crush and radial indentation, the main deformation occurs in a radial direction. The three-point bending setup, shown above, creates deformation in axial direction, caused by the bending motion, and in a radial direction, caused by the flat impactor. For the relevant part of the three-point bending deformation-before a short circuit occurs-the deformation happens mostly in a radial direction.

Figure $6 \mathrm{~A}$ shows the test result of cells with $100 \%$ SOC and $0 \%$ SOC for the loadcase radial crush impactor. A correlation between force drop and short circuiting can be observed, which was expected. Xia et al. [17] also identified the force drop as an indicator for a short circuit. The cells show a higher force level for $100 \%$ SOC compared to $0 \%$ SOC at the same deformation range. This higher force level can obtain from different reasons [18]. A charged cell has a higher packing density, caused by the swelling of the anode. When force is applied, this leads to a higher level of internal friction. The swollen anode also has a higher bending stiffness. Finally, lithium ions can induce mechanical stresses which also heightens the stiffness of the jellyroll. The earliest detections of short circuits appear at the same displacement, of $5.6 \mathrm{~mm}$, for both states of charge. Figure 6B shows the deformed specimen of test 01 at $100 \%$ SOC. 


\section{Mechanical Modelling of an $\mathbf{1 8 6 5 0}$ Lithium-Ion Battery Cell}

Within the scope of this paper, a macro-mechanical cell model for a type-18650 lithiumion battery is developed. The following steps, which are also shown in Figure 7, are needed for the validation of the model:

- $\quad$ cell-case testing (see Section 2)

- cell testing (see Section 2)

- model build-up

- cell case-model validation/optimization

- cell model validation/optimization.

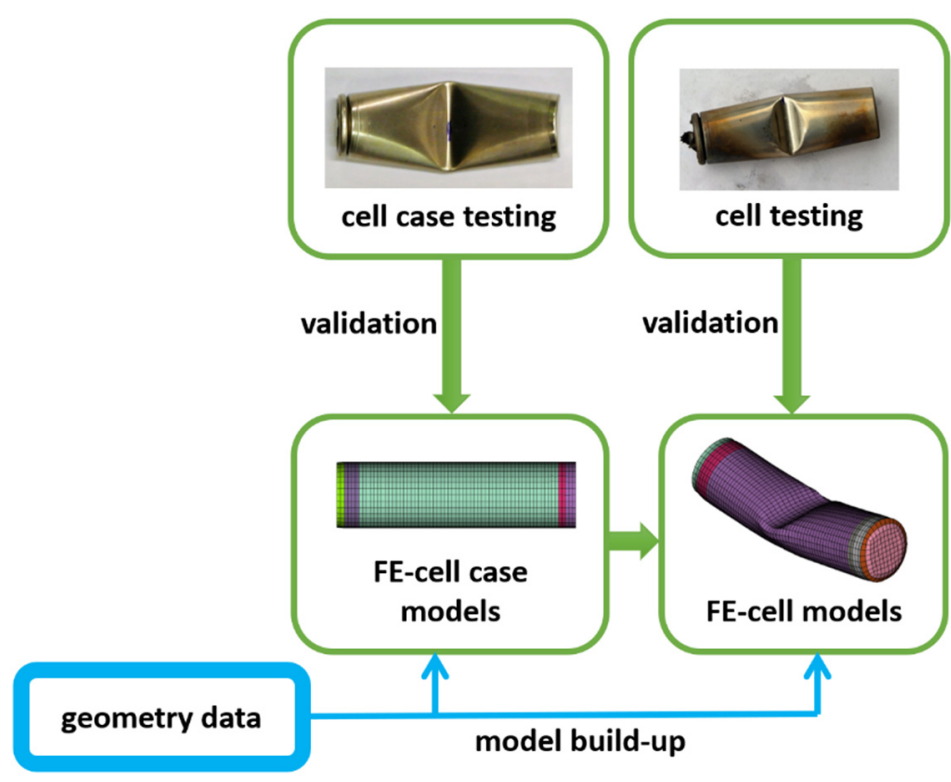

Figure 7. FE-model development steps.

\section{Model Build-Up and Validation}

The finite element model is built up using the representative volume element approach. As described above, this method is commonly used in crash simulation to model the jellyroll part of the battery cell. To create a universally useable simulation model, two different finite element solvers, Abaqus and LS-DYNA, are used. The model is first built up in Abaqus and then translated to LS-DYNA. The translated model is not changed any further, to keep both models comparable.

The cell, as well as the FE-model, are shown in Figure 8. Details of the cell, such as the contact and the notch at the top part are omitted to reduce calculation time. Due to the deep-drawing process in which the cell cup is produced, the material thickness varies in different parts of the cell cup. In the model, this is addressed by defining different parts with different shell thicknesses. 


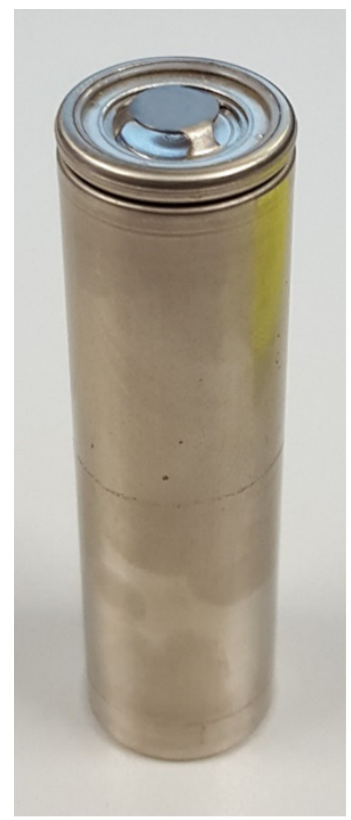

A

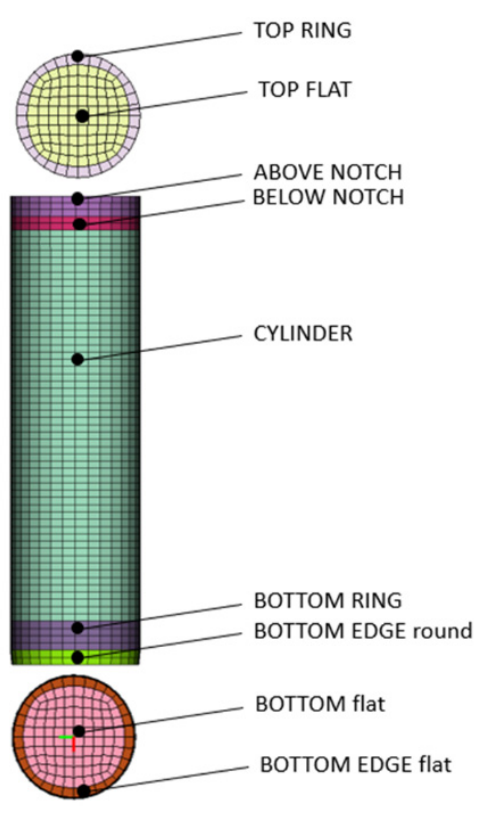

B

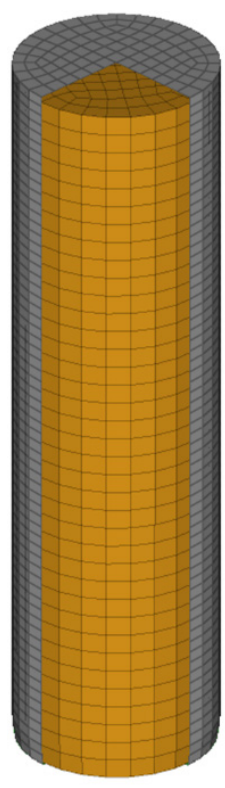

C

Figure 8. (A) 18650 cylindrical lithium-ion cell; (B) cell-cup model; (C) cell model also showing jellyroll.

The material used to simulate the cell cup is a steel model. Shell thicknesses, as mentioned above, vary between $0.23 \mathrm{~mm}$ and $0.31 \mathrm{~mm}$.

Figure 9 shows a comparison of force-displacement curves gained from the testing and simulation of the cell cup. Figure 10 shows a comparison of deformation for both models.

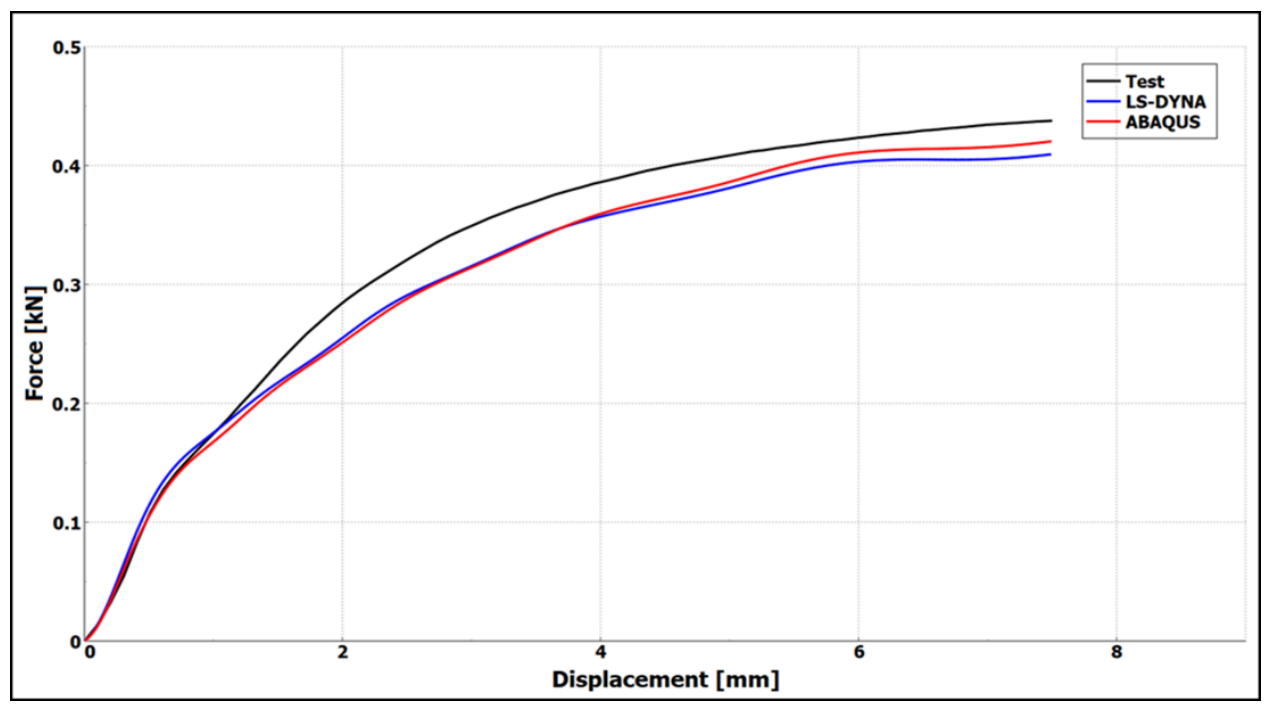

Figure 9. Force-displacement curves of the cell cup's load-case radial crush impactor. 


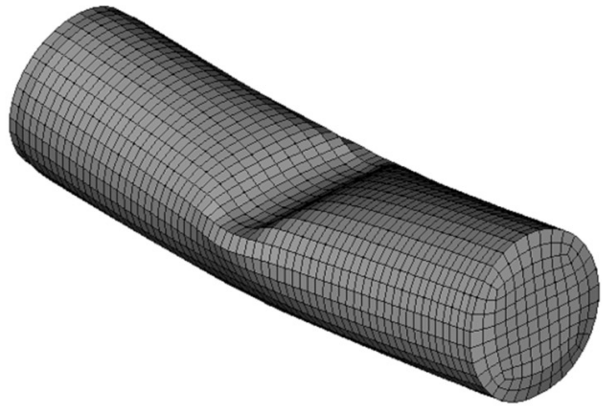

Abaqus

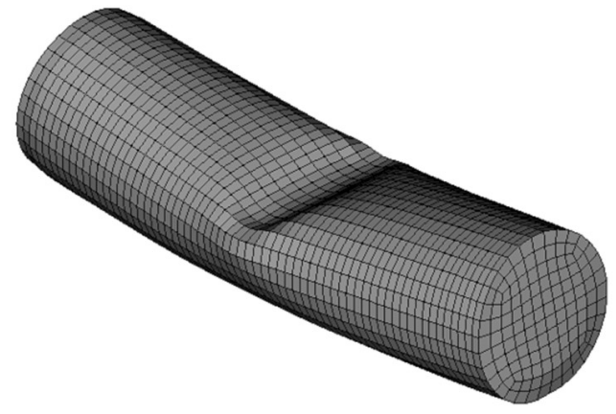

LS-DYNA

Figure 10. Simulation of deformation-load-case radial crush impactor.

There is a good correlation between the testing and simulation results. Also, the results of both simulations fit together very well.

Jellyroll Material:

The jellyroll itself is modelled by a solid mesh, as can be seen in Figure 8C. A honeycomb material is used to represent the jellyroll. This material has several advantages. It features orthotropic behaviour, where the properties in three orthogonal directions can be adjusted independently without lateral contraction. The material model was first created for Abaqus. Material properties were optimized in LS-OPT using the force-displacement curves from testing. Finally, the material model was translated to LS-DYNA. There are differences between the honeycomb materials in the two solvers which will be described in the following.

For Abaqus, tension/compression and shear behaviour are defined via tangent moduli [19]. Figure 11 shows the tension/compression characteristic for the $x$ direction; $y$ and $z$ are defined analogously.

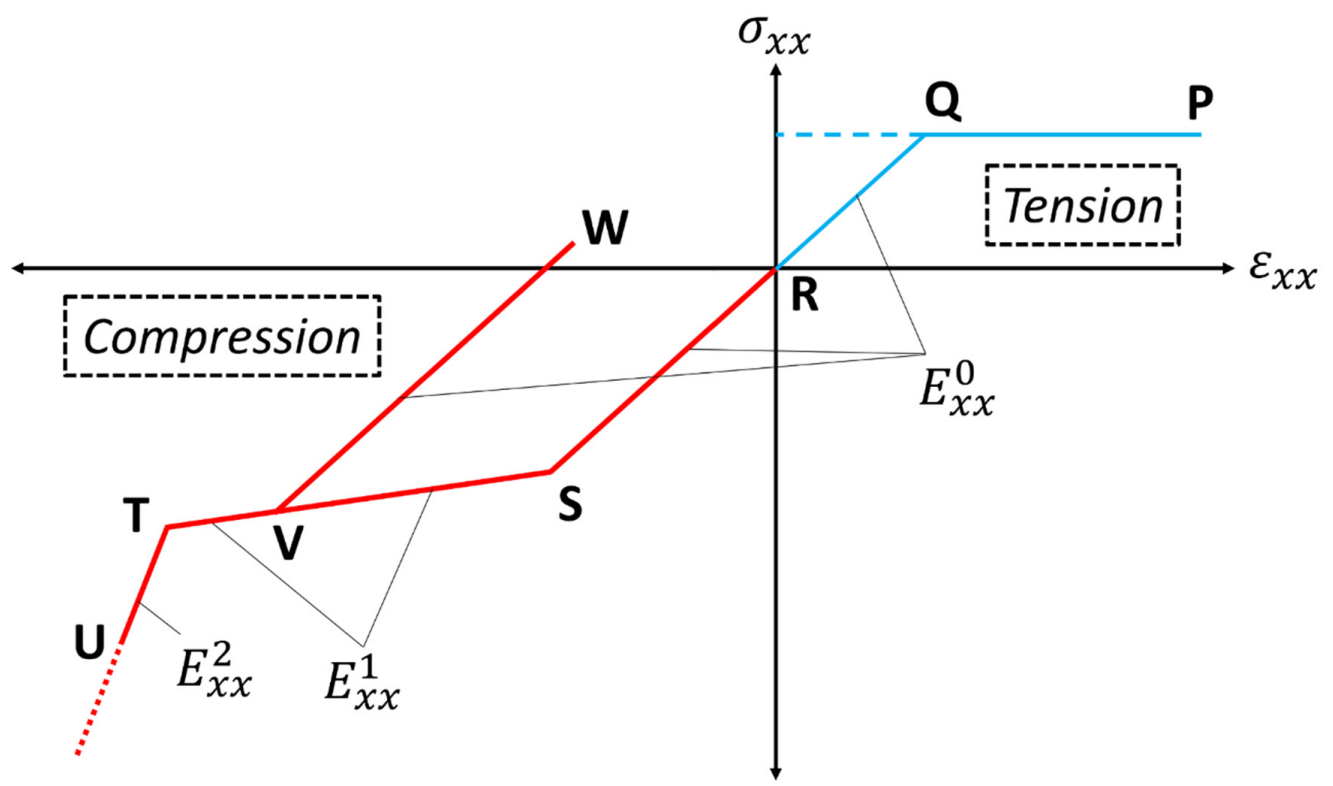

Figure 11. Tension/compression characteristic Abaqus.

$E_{x x}^{0}$ (defined by R-S), $E_{x x}^{1}$ (defined by S-T) and $E^{2}{ }_{x x}$ (defined by T-U) are the three tangent moduli. The stress at point $Q$ is the tensile stress above which the material has ideally plastic behavior. Points $\mathrm{V}$ and $\mathrm{W}$ mark the path for unloading. The first quadrant of this diagram corresponds to the tension characteristic whereas the third represents compression. 
Figure 12 describes the shear characteristic for the $x y$ direction; $y z$ and $z x$ are defined analogously.

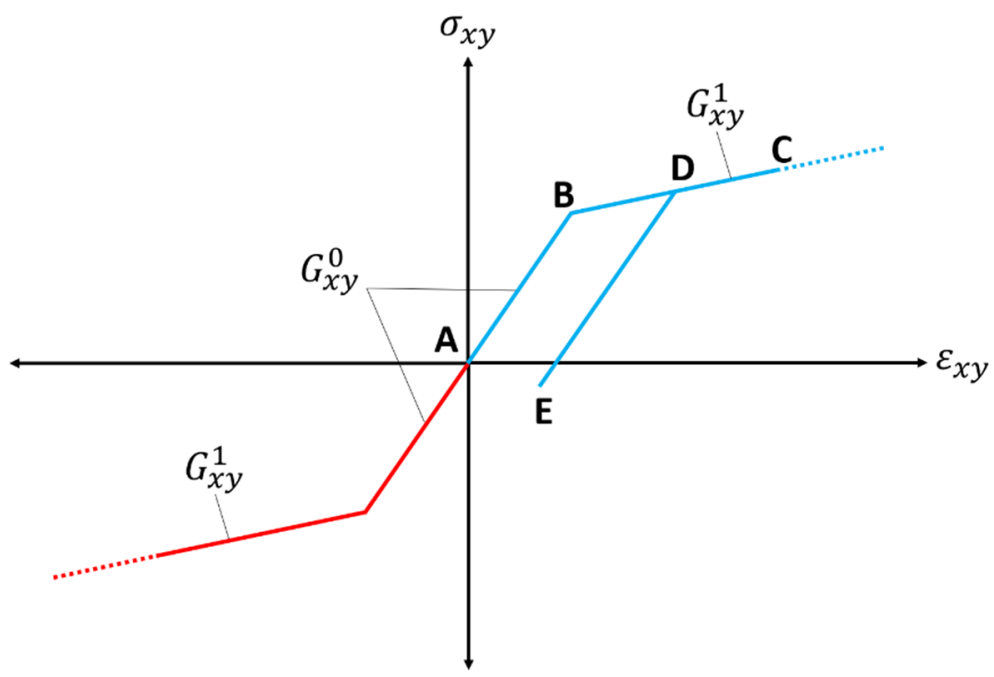

Figure 12. Shear characteristic in Abaqus.

The characteristic is very similar to tension/compression but only two tangent moduli are used. These are $G^{0} x y$, defined by A-B and $G^{1} x y$, defined by B-C.

For LS-DYNA, tension/compression in $x, y$ and $z$ as well as shear in $x y, y z$ and $z x$ are defined via stress-strain curves or load curves [20]. This is shown in the diagram in Figure 13.

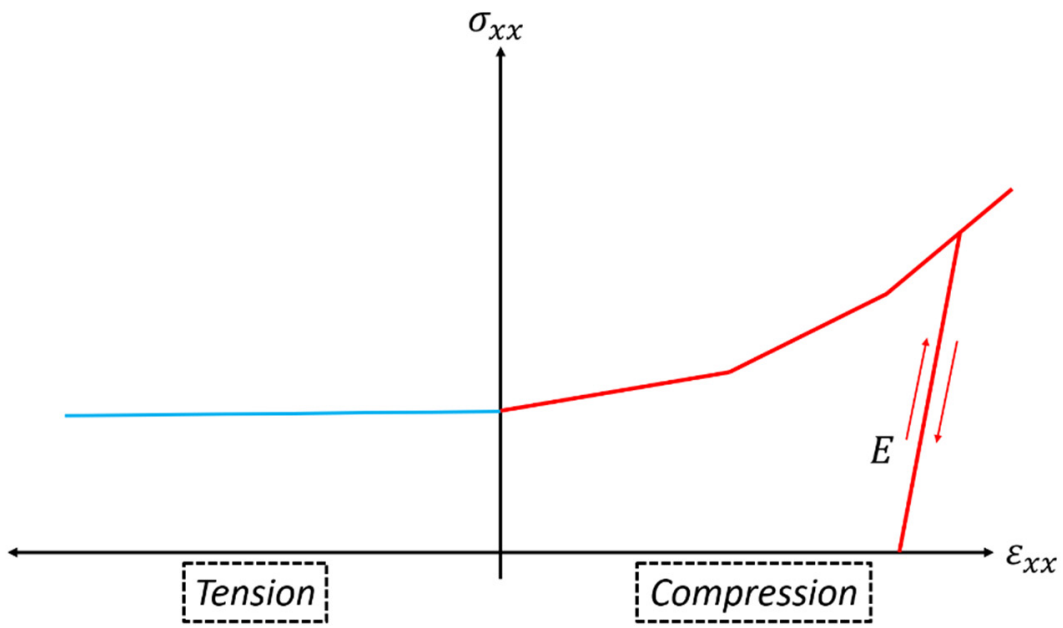

Figure 13. Load curve LS-DYNA.

These load curves are defined in tabular form and only in the first and second quadrant. This means the negative stresses are also defined as positive. The first quadrant corresponds to compression and the second to tension. The load curves use total strain and are reached via the slope defied by the Young's modulus.

The translation of the material parameters from Abaqus to LS-DYNA is done via reference points in the stress-strain diagrams, as depicted in Figure 14. 


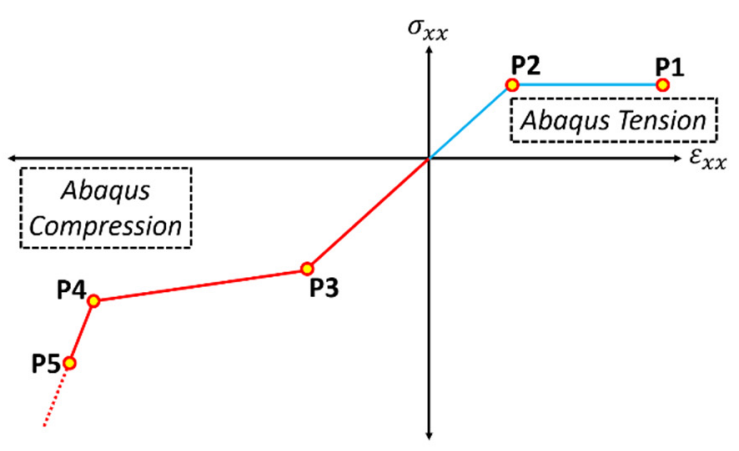

A

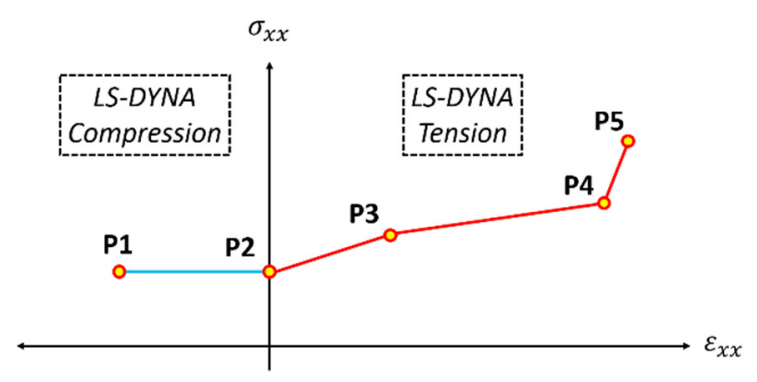

B

Figure 14. Stress-strain characteristics for Abaqus (A) and LS-DYNA (B).

The Points P1 through P5 are taken from the Abaqus model and translated to the LS-DYNA model. P2, which has a non-zero strain in Abaqus, has to be shifted to zero strain. The excluded part represents the elastic part of the characteristic, which is not included in the LS-DYNA load curve but defined separately by Youngs' modulus.

The final comparison of the force-displacement curves obtained from testing, and the simulation is shown to beexemplary for the load-case radial crush impactor in Figure 15.

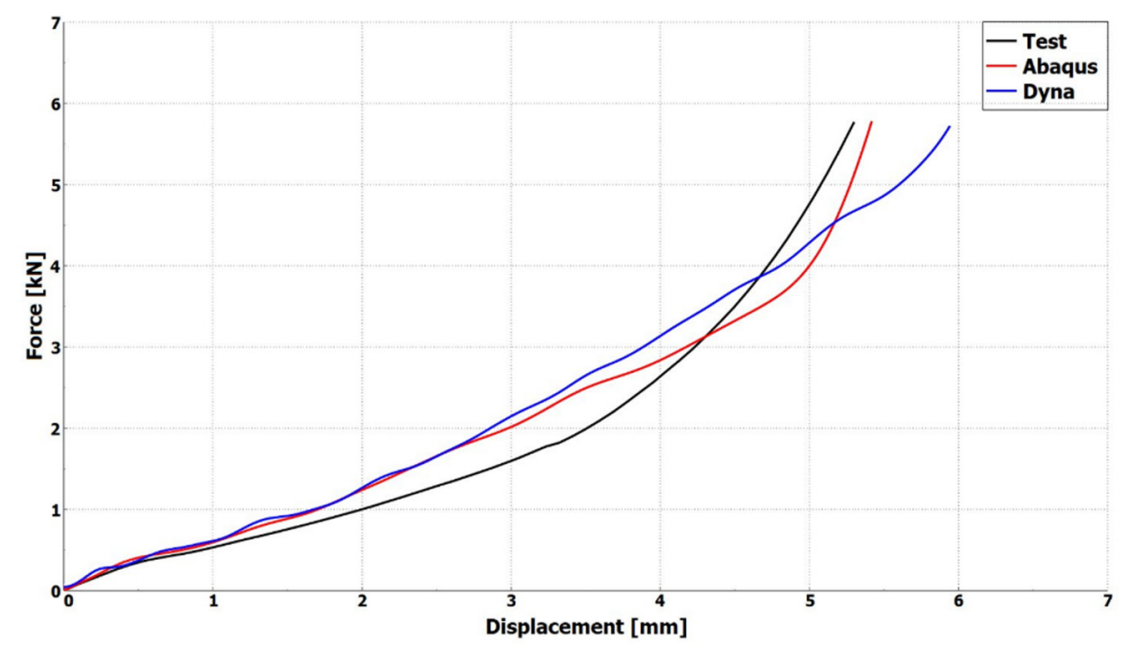

Figure 15. Force-displacement curves of the cell load-case radial crush impactor.

One can see a good correlation between testing (black) and simulation results, especially at the beginning. Between $1 \mathrm{~mm}$ and $5 \mathrm{~mm}$ of displacement the simulated forces are higher than measured ones. There are also deviations between the two simulations using different solvers (Abaqus-red, LS-DYNA-blue). This is most likely caused by the differences in material formulation, as mentioned above. The simulation model was validated for four different load cases (Table 2). The final model is always a compromise that has to work for all load cases.

The presented model is only validated for the used type of cell under quasistatic conditions. Cells of different materials will behave differently. The speed of mechanical loading can also have an influence on cells' behaviours [21].

\section{Virtual Short Circuit Detection}

The validated finite element simulations (see details in Section 3) of the 18650 cylindrical lithium-ion battery and the testing results of the mechanical cell tests (Section 2) serve as the basis for the creation of short-circuit criteria. These criteria should be useable in the post-processing and have to detect short circuits at the same values of displacement as 
observed in the physical tests. Table 3 summarizes the values of impactor displacement at the occurrence of a short circuit for the four used load cases.

Table 3. Impactor displacement at the occurrence of a short circuit for four tested cell-load cases.

\begin{tabular}{cc}
\hline Load Case & Impactor Displacement at Short Circuit/mm \\
\hline axial crush & 5.5 \\
radial crush & 5.6 \\
radial crush impactor & 5.4 \\
three-point bending & 6.5 \\
\hline
\end{tabular}

As mentioned in Section 1.1.2, there are several methods for virtual short-circuit prediction. Most of these are used and tested in the following.

The Mohr-Coulomb criterion was not used. It uses the fracture of the jellyroll, which was not detected during the tests. The force-drop criterion was not used, because it only works in a simplified setup, where it is easy to pinpoint and where the force is measured. Since the model is intended to be usable in complex 3D-loading scenarios e.g., a full-scale vehicle simulation, this is difficult to realize.

\subsection{Strain Based Short Circuit Criteria}

The jellyroll, in the cell model, is simulated using solid elements. During postprocessing, strains of each element are analysed for every time step.

The strain-based criteria are tested in two ways, local and global. The local approach looks at each element individually. Should the quantity chosen for the short-circuit criterion exceed a certain threshold value, a short circuit is expected. This approach focuses on areas of high deformation, where ruptures in the physical jellyroll could occur and cause a short circuit.

The global approach works quite similarly. It calculates the mean value from a chosen quantity of jellyroll elements and compares it to a threshold value. Should this mean value exceed the threshold, a short circuit is expected analogously. This approach considers the overall deformation of the cell, which might cause a short circuit even without high deformations at one spot.

The tested short-circuit criteria are discussed in the following. Maximum Principal Strain:

For this criterion, the maximum absolute value of the three principal strains, $\varepsilon_{1}, \varepsilon_{2}$ and $\varepsilon_{3}$,

$$
\varepsilon_{\operatorname{Max} P r}=\operatorname{MAX}\left(\left|\varepsilon_{1}\right|,\left|\varepsilon_{2}\right|,\left|\varepsilon_{3}\right|\right)
$$

is calculated, which results in the maximum principal strain $\varepsilon_{M a x P r}$.

Volumetric Strain:

The sum of the three principal strains,

$$
\varepsilon_{V o l}=\varepsilon_{1}+\varepsilon_{2}+\varepsilon_{3}
$$

is calculated and gives the volumetric strain.

Von Mises-Equivalent Strain:

For this criterion, equivalent strain is calculated

$$
\varepsilon_{E q u}=\sqrt{\frac{2}{3} *\left(\varepsilon_{x}^{2}+\varepsilon_{y}^{2}+\varepsilon_{z}^{2}+\frac{1}{2} *\left(\varepsilon_{x y}^{2}+\varepsilon_{y z}^{2}+\varepsilon_{z x}^{2}\right)\right)},
$$

using the strain values of the stress tensor, $\varepsilon_{x}, \varepsilon_{y}, \varepsilon_{z}, \varepsilon_{x y}, \varepsilon_{y z}$ and $\varepsilon_{z x}$, gained from simulation.

Principal Strain (2D) and Strain in the Axis Direction: 
For this criterion, the principal strains are calculated for the two-dimensional case, based on the two radial directions orthogonal to the cell axis. For these two principal strains,

$$
\varepsilon_{1,2}=\frac{\varepsilon_{x}+\varepsilon_{y}}{2} \mp \sqrt{\left(\frac{\varepsilon_{x}-\varepsilon_{y}}{2}\right)^{2}+\varepsilon_{x y}^{2}}
$$

the strain values from the simulation are used.

Three of the four load cases mainly deform the cells in radial directions, whereas, in the fourth, the cells are deformed mainly in the axial direction. Threshold values working for the three radial load cases will likely not be reached in the axial case.

The 2D principal strain criterion assesses strain in the directions affected by the radial load cases. For the axial-crush load case, strain in the axial direction, $\varepsilon_{z}$, is taken as an additional criterion. For this criterion to work, the threshold value should not be reached in any of the three radial load cases.

\subsection{Stress Based Short-Circuit Criteria}

For these criteria, during post-processing, the stresses of the jellyroll elements are analysed for every time step.

The stress-based criteria are tested in two ways, locally and globally. These two approaches are the same as discussed above for the strain-based short-circuit criteria.

Maximum principal stress:

For this criterion, the maximum absolute value of the three principal stresses, $\sigma_{1}, \sigma_{2}$ and $\sigma_{3}$,

$$
\sigma_{\mathrm{MaxPr}}=\operatorname{MAX}\left(\left|\sigma_{1}\right|,\left|\sigma_{2}\right|,\left|\sigma_{3}\right|\right)
$$

is calculated, the maximum principal stress $\sigma_{M a x P r}$.

Von Mises equivalent stress:

For this criterion, the equivalent stress $\sigma_{E q u}$

$$
\sigma_{E q u}=\sqrt{\sigma_{x}^{2}+\sigma_{y}^{2}+\sigma_{z}^{2}-\sigma_{x} * \sigma_{y}-\sigma_{y} * \sigma_{z}-\sigma_{z} * \sigma_{x}+3 *\left(\sigma_{x y}^{2}+\sigma_{y z}^{2}+\sigma_{z x}^{2}\right)}
$$

is calculated using the stress values of the stress tensor, $\sigma_{x}, \sigma_{y}, \sigma_{z}, \sigma_{x y}, \sigma_{y z}$ and $\sigma_{z x}$, gained from simulation.

\subsection{Geometric Short Circuit Criteria}

For these criteria, the deformation parameters of the cell are analysed for every time step. These parameters are in general deduced from nodal displacements. Should such a deformation parameter exceed a certain threshold value, a short circuit is detected. In general, nodal positions of the finite element mesh are analysed.

Axial and Radial Geometric Criterion:

For the geometric approach, the problem is split into two parts; the axial geometric criterion and the radial geometric criterion. This is justified by the fact that the short circuit is caused by different mechanisms in the axial and radial loading of the cell. In the radial case, the layers of the jelly roll start rupturing if the load exceeds a certain level. The ruptured layers then cause a short circuit. In the axial case, the conductive parts connecting the jellyroll and battery terminals are damaged, thereby causing a short circuit.

The axial geometric criterion is based on the distance between the flat sides at the top and bottom of the cylindrical cell. Two groups of nodes are defined. One includes all nodes from the top side, the other includes all nodes of the bottom side (see Figure 16). If caused by deformation, the distance between any top-node and any bottom-node falls below the threshold value, a short circuit is detected. The purpose of this criterion is the detection of a short circuit for axial loading of the battery cell. In order for the criterion to be feasible, 
the threshold value must not be reached in any of the radial load cases, except at the point where a short circuit should be detected therein.

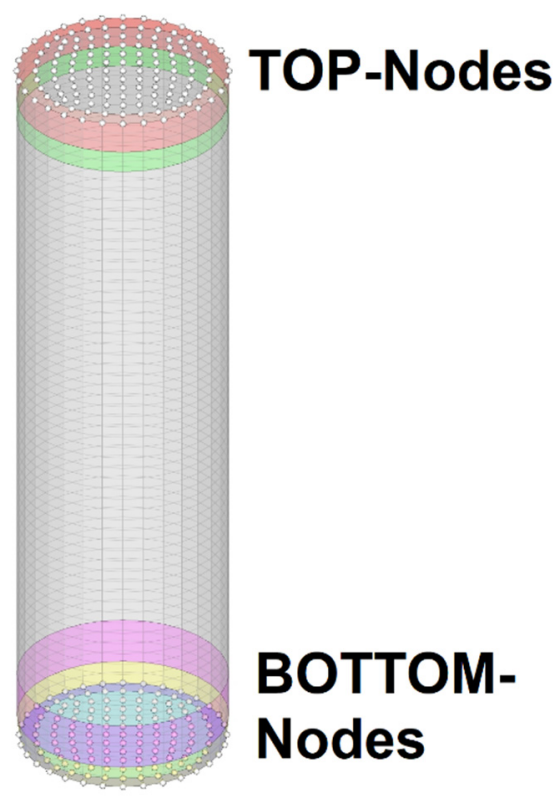

Figure 16. Cell model with the top and bottom nodes used for the axial geometric criterion.

The radial geometric criterion is based on the distance between pairs of nodes located on directly opposite points of the cell-cylinder mantle. All nodes on the cylinder mantle are used and, altogether, 1008 pairs of nodes are defined. An example of such a pair is shown in Figure 17.
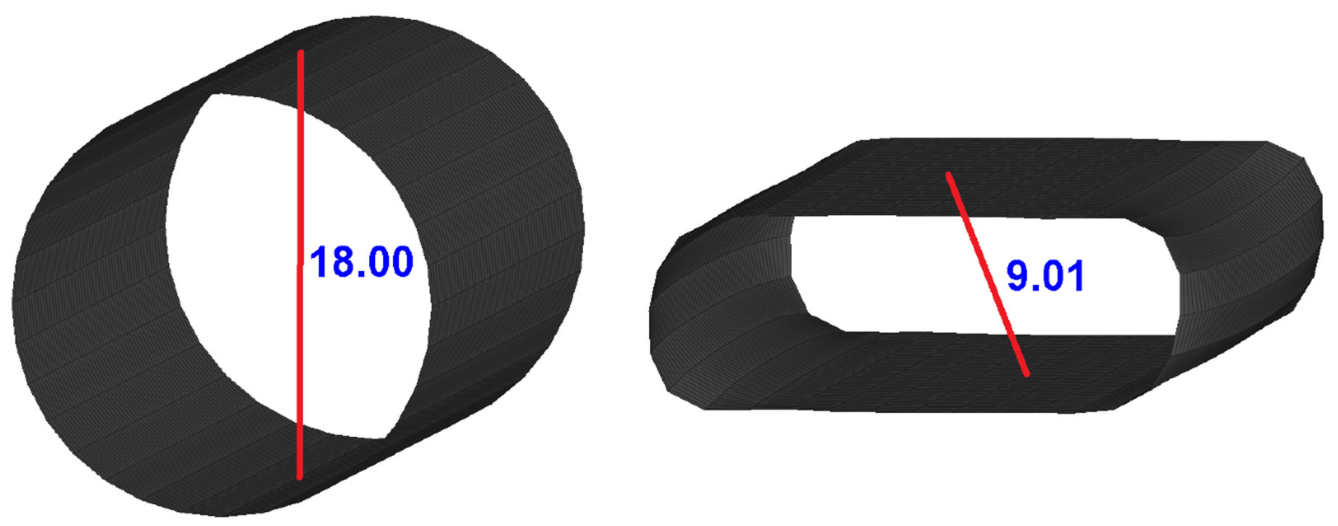

Figure 17. An exemplary pair of nodes on the cell case used for the radial geometric criterion.

Figure 17 shows the absolute nodal distance in millimetres before and after deformation.

If caused by deformation, the distance between any such pair of nodes falls below the threshold value, the short circuit is detected. The purpose of this criterion is the detection of a short circuit for radial loading of the battery cell. For it to work it is necessary that the threshold value is not reached in the axial-crush load case, except after the point where a short circuit should be detected therein.

\section{Results}

In this chapter, the results of the analysis of the different criteria used for the virtual detection of a short circuit, described in the preceding section, are presented. Every shortcircuit criterion was tested for the two solvers, Abaqus and LS-DYNA, and for the four mechanical load cases used for testing the battery cells. The result for each such test is the 
value of the impactor displacement at which the short circuit occurred. These values are compared to those from testing. Finally, to assess the different short circuit criteria, two additional values are analysed.

The first value is the maximum deviation in displacement at short circuit between testing and simulation of any of the four load cases.

The second value is the maximum deviation in displacement at short circuit between the solvers for any of the four load cases.

These values are presented in Table 4. For better visualization, the two values assessing the criteria are colour coded. With respect to deviations from testing, values up to $1.5 \mathrm{~mm}$ are green, values between $1.5 \mathrm{~mm}$ and $2.0 \mathrm{~mm}$ are orange and values above $2.0 \mathrm{~mm}$ are red. With respect to deviations between solvers, values up to $0.5 \mathrm{~mm}$ are green, values between $0.5 \mathrm{~mm}$ and $1.0 \mathrm{~mm}$ are orange and values above $1.0 \mathrm{~mm}$ are red.

Table 4. Results for virtual short-circuit detection for four mechanical load cases using different criteria.

\begin{tabular}{|c|c|c|c|c|c|c|c|}
\hline 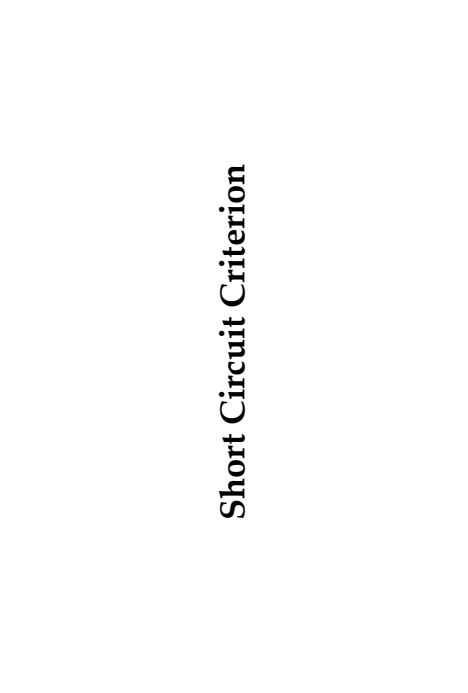 & 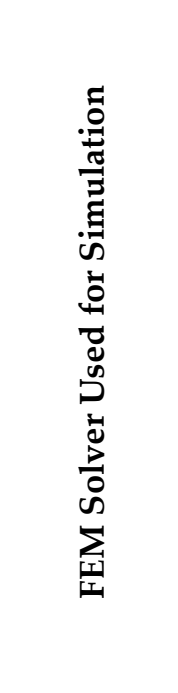 & 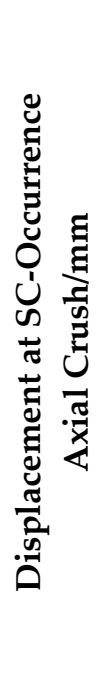 & 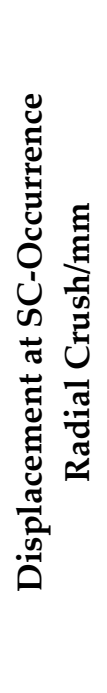 & 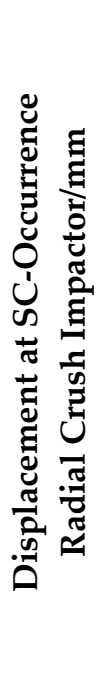 & 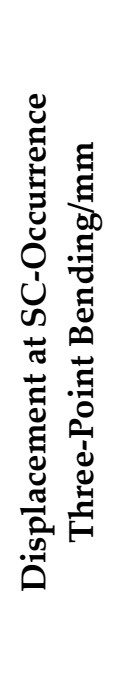 & 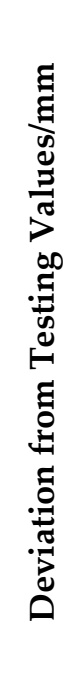 & 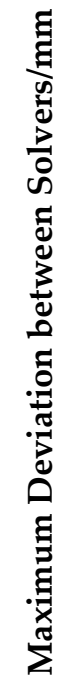 \\
\hline \multirow{2}{*}{ volumetric strain - local } & Abaqus & * & 5.62 & 3.74 & 4.56 & 1.92 & \multirow{2}{*}{0.09} \\
\hline & LS-DYNA & $*$ & 5.62 & 3.83 & 4.51 & 1.97 & \\
\hline \multirow{2}{*}{ volumetric strain - global } & Abaqus & 4.42 & 3.57 & 5.36 & 4.85 & 2.08 & \multirow{2}{*}{0.75} \\
\hline & LS-DYNA & 4.01 & 4.32 & 5.30 & 4.37 & 2.11 & \\
\hline \multirow{2}{*}{ equivalent strain - local } & Abaqus & $*$ & 5.62 & 3.78 & 5.10 & 1.58 & \multirow{2}{*}{1.74} \\
\hline & LS-DYNA & * & 4.23 & 5.36 & 6.84 & 1.42 & \\
\hline \multirow{2}{*}{ equivalent strain - global } & Abaqus & $*$ & 3.04 & 5.36 & 4.51 & 2.25 & \multirow{2}{*}{0.24} \\
\hline & LS-DYNA & * & 3.32 & 5.36 & 4.75 & 2.33 & \\
\hline \multirow{2}{*}{ equivalent stress - local } & Abaqus & 4.14 & 5.46 & 2.85 & 3.36 & 3.12 & \multirow{2}{*}{0.65} \\
\hline & LS-DYNA & 3.49 & 5.62 & 2.66 & 3.36 & 3.12 & \\
\hline \multirow{2}{*}{ equivalent stress - global } & Abaqus & 3.28 & 5.51 & 4.90 & 5.10 & 2.26 & \multirow{2}{*}{0.21} \\
\hline & LS-DYNA & 3.36 & 5.72 & 5.00 & 4.90 & 2.18 & \\
\hline \multirow{2}{*}{ max. principal strain -local } & Abaqus & $*$ & 5.10 & 2.70 & 3.00 & 3.48 & \multirow{2}{*}{3.44} \\
\hline & LS-DYNA & $*$ & 3.96 & 5.36 & 6.44 & 1.69 & \\
\hline \multirow{2}{*}{ max. principal strain - global } & Abaqus & 5.25 & 3.57 & 5.30 & 4.85 & 2.08 & \multirow{2}{*}{3.32} \\
\hline & LS-DYNA & 3.16 & 1.68 & 1.98 & 1.92 & 4.56 & \\
\hline
\end{tabular}


Table 4. Cont.

\begin{tabular}{|c|c|c|c|c|c|c|c|}
\hline 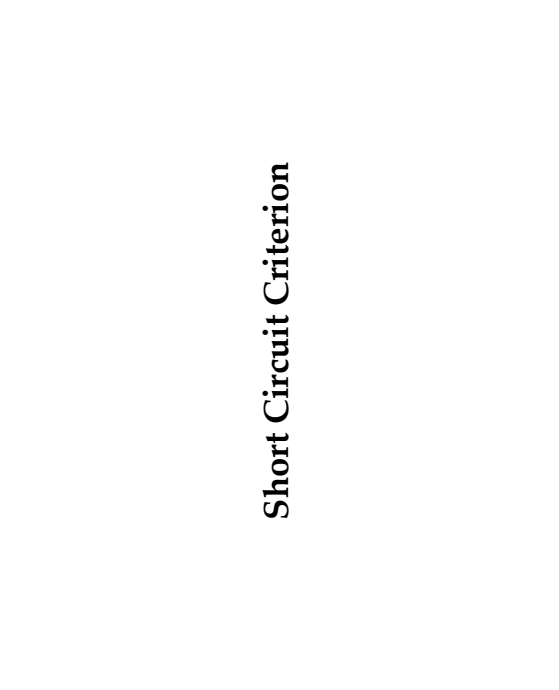 & 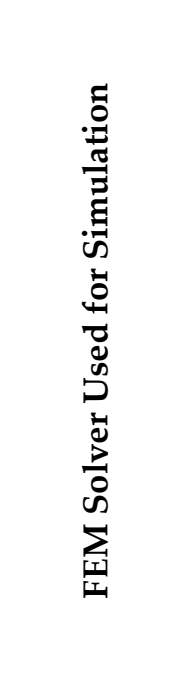 & 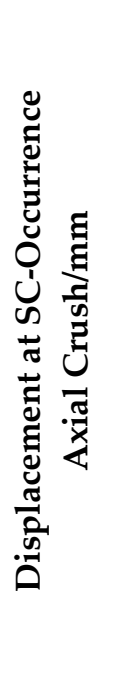 & 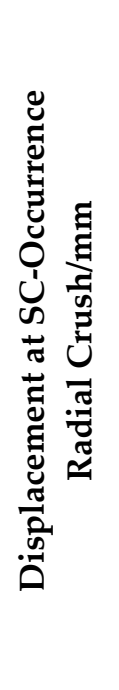 & 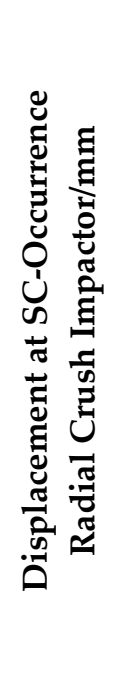 & 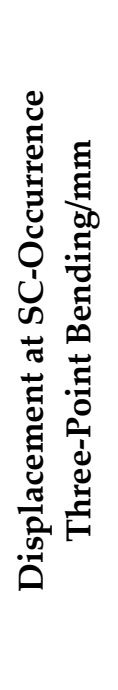 & 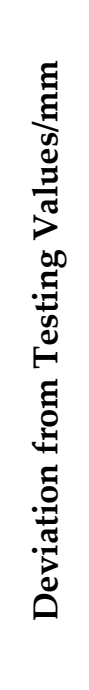 & 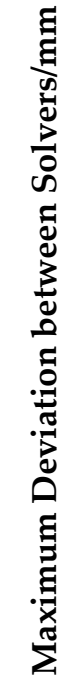 \\
\hline \multirow{2}{*}{ max. principal stress - local } & Abaqus & 4.32 & 5.41 & 2.63 & 3.04 & 3.44 & \multirow{2}{*}{-1.04} \\
\hline & LS-DYNA & 3.28 & 5.46 & 2.56 & 3.04 & 3.44 & \\
\hline \multirow{2}{*}{ max. principal stress - global } & Abaqus & 3.28 & 5.62 & 5.25 & 5.57 & 2.26 & \multirow{2}{*}{0.27} \\
\hline & LS-DYNA & 3.28 & 5.36 & 5.30 & 5.30 & 2.26 & \\
\hline \multirow{2}{*}{ principal strain $2 \mathrm{D}-$ local } & Abaqus & $*$ & 4.66 & 3.78 & 6.44 & 1.58 & \multirow{2}{*}{3.08} \\
\hline & LS-DYNA & $*$ & 5.62 & 2.81 & 3.36 & 3.12 & \\
\hline \multirow{2}{*}{ principal strain $2 \mathrm{D}-$ global } & Abaqus & * & 3.20 & 5.36 & 4.05 & 2.45 & \multirow{2}{*}{1.53} \\
\hline & LS-DYNA & $*$ & 3.36 & 4.70 & 2.52 & 3.96 & \\
\hline \multirow{2}{*}{ axial and radial geometric criterion } & Abaqus & 5.51 & 4.19 & 4.51 & 6.38 & 1.46 & \multirow{2}{*}{0.30} \\
\hline & LS-DYNA & 5.51 & 4.49 & 4.79 & 6.53 & 1.16 & \\
\hline testing values & & 5.54 & 5.65 & 5.36 & 6.48 & & \\
\hline
\end{tabular}

* For the axial-crush load case several values are missing. In these cases, no short circuit occurred, as the values for the given criterion were by far smaller than for the other three load cases. Therefore, axial crush was excluded, here. We have refrained from using an additional axial criterion, as was done for the geometric approach, because the results for the radial tests in these cases were not as good as with the geometric criteria.

The strain criterion in the axial direction (Section 4.1) was omitted, as the analysis of the 2D principal strain criterion showed no promising results and these two criteria would have only worked in combination.

The combination of axial and radial geometric criterion offered the best results for the short-circuit measurement, compared with test results. In addition, it worked for both FEM solvers and there was little deviation in the results between them. The used threshold values are:

The axial geometric criterion was $61.6 \mathrm{~mm}$, which is $94.8 \%$ of the original cell length for the Abaqus and LS-DYNA solvers.

The radial geometric criterion was a minimal node-pair distance of $14.7 \mathrm{~mm}(81.7 \%$ of original diameter) for LD-DYNA and $15.0 \mathrm{~mm}$ ( $83.3 \%$ of original diameter) for Abaqus.

\section{Conclusions}

A finite element model of a cylindrical Li-ion battery cell for two different solvers, validated by physical tests, was presented. Several methods of virtual short-circuit detection were explored and assessed. Finally, a method using two geometric short-circuit criteria was developed to produce satisfactory results in predicting short circuits in all four load cases, with both solvers. To the authors' knowledge, no other publication has featured a validated model working with two different FEM solvers, and few publications 
have used approaches for both the axial and radial mechanical loading of cylindrical cells. Raffler et al. [5] published a model based on the beam method that produced very good results for axial and radial loadings, though a three-point bending load case was not used there. This load case presents a special loading scenario, combining primarily axial compression and, to a lesser degree, radial compression [3]. Wang et al. [22] achieved good results for the same four load cases used in the current work. They used detailed layered simulation model, which, due to calculation time, would probably not be applicable for large-scale simulations.

The current battery model with short circuit prediction can now be used in the simulation of larger assemblies, such as battery modules, car battery packs or even complete vehicle simulations. For example, it is possible to simulate a full vehicle crash and gain information on which of the individual battery cells installed in the car might suffer a short circuit due to mechanical abuse during the crash. This enables the crashworthy design and integration of battery packs in vehicles.

Author Contributions: Conceptualization, C.B. and P.D.; finite element modelling methodology, K.J, C.B. and M.M.; software, K.J.; validation, K.J. and C.B.; formal analysis, C.B. and K.J.; investigation, C.B. and K.J.; data curation, K.J.; writing—original draft preparation, K.J. and K.I.; writing—review and editing, C.B., K.J., P.D. and K.I.; visualization, K.J.; supervision, C.B.; project administration, C.B.; funding acquisition, C.B. All authors have read and agreed to the published version of the manuscript.

Funding: The publication was written at VIRTUAL VEHICLE Research GmbH in Graz and is partially funded by the COMET K2-Competence Centers for Excellent Technologies Program of the Federal Ministry for Transport, Innovation and Technology (BMVIT), the Federal Ministry for Digital and Economic Affairs (BMDW), the Austrian Research Promotion Agency (FFG), the Province of Styria and the Styrian Business Promotion Agency (SFG). This work was conducted as part of the research project SafeBattery. The K-project SafeBattery (FFG project number 863073) is funded by the BMVIT, BMDW, Austria and Land Steiermark within the framework of the COMET_Competence Centers for Excellent Technologies program. The COMET program is administered by the FFG.

Acknowledgments: The authors thank the consortium members of the SafeBattery project for their valuable input to this work. The Authors also thank Jonas Pucher for his contribution in coding the post-processing tool that was used for the virtual short-circuit prediction analysis.

Conflicts of Interest: The authors declare no conflict of interest. The funders had no role in the design of the study; in the collection, analyses or interpretation of data; in the writing of the manuscript, or in the decision to publish the results. 


\section{Appendix A}

Table A1. Summary of the publications regarding mechanical testing of cylindrical cell 18650.
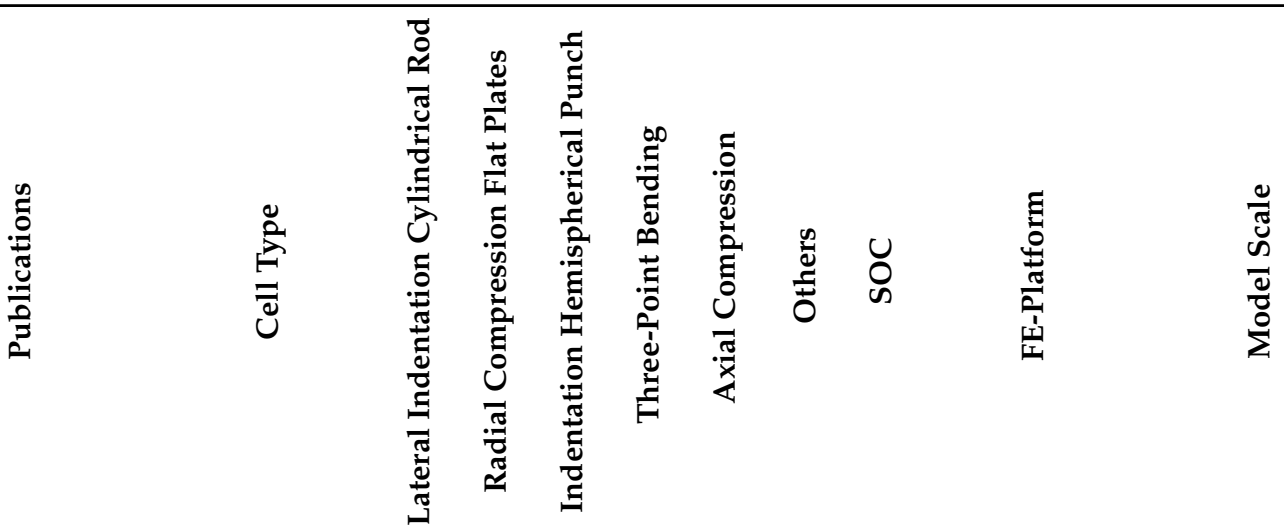

E. Sahraei et al., 2012 [3] cylindrical cell 18650 $\mathrm{x}$

$\mathrm{x} \quad \mathrm{x}$

$10 \% \quad$ LS-DYNA

meso-scale

cylindrical nickel-cobalt

L. Greve et al., 2012 [10] virtual cell, (GAIA HP 602030

NCA-45 $\mathrm{Ah} / 162 \mathrm{Wh}$ ) performance macro-scale solution

(VPS)
A very good correlation has been obtained between the test results and numerical simulation.

A very good correlation was obtained between the test results and

numerical simulation.

T. Wierzbicki, E. cylindrical Sahraei 2013 [4] cell 18650 $x$

$10 \%$

LS-DYNA

RVE

Good agreement between simulation and corresponding tests

The jellyroll failure began at about 4-5 $\mathrm{mm}$ of displacement.

The outer shell developed an axisymmetric fold. No internal failure

Y. Xia et al., $2014 \quad$ cylindrical $x \quad-\quad$ LS-DYNA meso-scale point in the jellyroll.

[17] cell 18650

After $14 \mathrm{~mm}$ of deformation, jellyroll elements started to fail, ultimately forming two longitudinal cracks at a $15-\mathrm{mm}$ punch intrusion

cylindrical nickel-cobalt

J. Xu et al., 2015 [11] oxide (NCA) cell, (GAIA, HP 602030

NCA-45
A good agreement between experiment and simulation results 
Table A1. Cont.

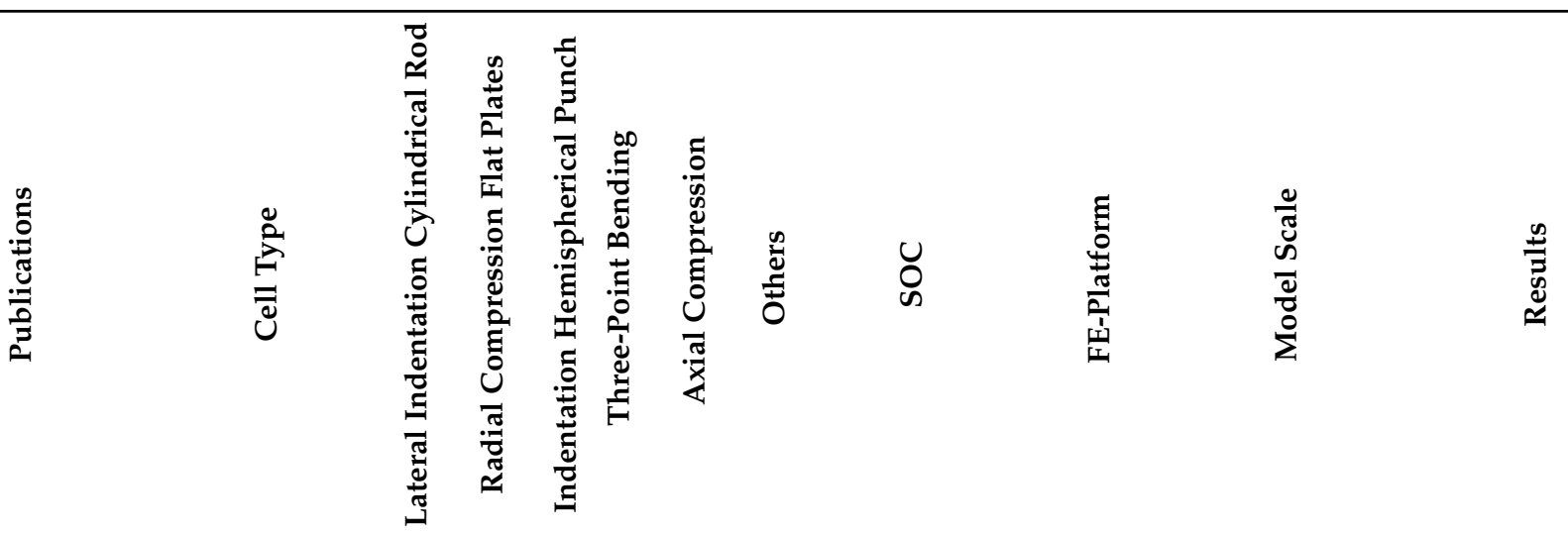

\begin{tabular}{|c|c|c|c|c|c|c|c|c|c|c|}
\hline $\begin{array}{c}\text { J. Zhu et al., } 2016 \\
\text { [23] }\end{array}$ & $\begin{array}{l}\text { cylindrical } \\
\text { cell } 18650\end{array}$ & & & & $x$ & & $0 \%$ & $\begin{array}{l}\text { ABAQUS/ } \\
\text { Explicit }\end{array}$ & meso-scale & $\begin{array}{l}\text { Good agreement } \\
\text { between tests and } \\
\text { simulation. }\end{array}$ \\
\hline $\begin{array}{l}\text { L. Tang et al., } \\
2017 \text { [24] }\end{array}$ & $\begin{array}{l}\text { cylindrical } \\
\text { cell } 18650\end{array}$ & & $x$ & $x$ & & & - & $\begin{array}{l}\text { ABAQUS/ } \\
\text { Explicit }\end{array}$ & $\begin{array}{l}\text { macro- } \\
\text { scale }\end{array}$ & $\begin{array}{l}\text { Good agreement } \\
\text { between tests and } \\
\text { simulation. }\end{array}$ \\
\hline $\begin{array}{l}\text { B. Liu et al., } 2018 \\
\text { [12] }\end{array}$ & $\begin{array}{l}\text { cylindrical } \\
\text { cell } 18650\end{array}$ & $x$ & $x$ & & & & & ABAQUS & meso-scale & $\begin{array}{l}\text { Good agreement } \\
\text { between tests and } \\
\text { simulation. }\end{array}$ \\
\hline $\begin{array}{l}\text { W. Wang et al., } \\
2018 \text { [25] }\end{array}$ & $\begin{array}{l}\text { cylindrical } \\
\text { cell } 18650\end{array}$ & $\mathrm{x}$ & $\mathrm{x}$ & & & & $\begin{array}{l}\text { different } \\
\text { SOC }\end{array}$ & $\begin{array}{c}\text { LS- } \\
\text { DYNA }\end{array}$ & meso-scale & $\begin{array}{l}\text { Good agreement } \\
\text { between tests and } \\
\text { simulation. }\end{array}$ \\
\hline $\begin{array}{l}\text { L. Wang et al., } \\
2019 \text { [22] }\end{array}$ & $\begin{array}{l}\text { cylindrical } \\
\text { cell } 18650 \\
\text { (NCA) }\end{array}$ & $x$ & $x$ & $\mathrm{x}$ & $x$ & & $0 \%$ & $\begin{array}{c}\text { LS- } \\
\text { DYNA }\end{array}$ & meso-scale & $\begin{array}{l}\text { Good agreement } \\
\text { between tests and } \\
\text { simulation. }\end{array}$ \\
\hline $\begin{array}{l}\text { M. Sheikh et al., } \\
2020 \text { [26] }\end{array}$ & $\begin{array}{l}\text { cylindrical } \\
\text { cell } 18650 \\
\text { Samsung } \\
2200 \mathrm{mAh}\end{array}$ & $\mathrm{x}$ & $x$ & $x$ & & $x$ & $\begin{array}{l}\text { different } \\
\text { SOC } \\
(0 \%, 25 \% \text {, } \\
50 \% \text { and } \\
75 \%)\end{array}$ & $\begin{array}{c}\text { LS- } \\
\text { DYNA }\end{array}$ & meso-scale & $\begin{array}{l}\text { The model is } \\
\text { capable of } \\
\text { capturing cell } \\
\text { mechanical } \\
\text { response. }\end{array}$ \\
\hline
\end{tabular}


Table A2. Summary of the publications regarding the short circuit prediction due to mechanical deformations.

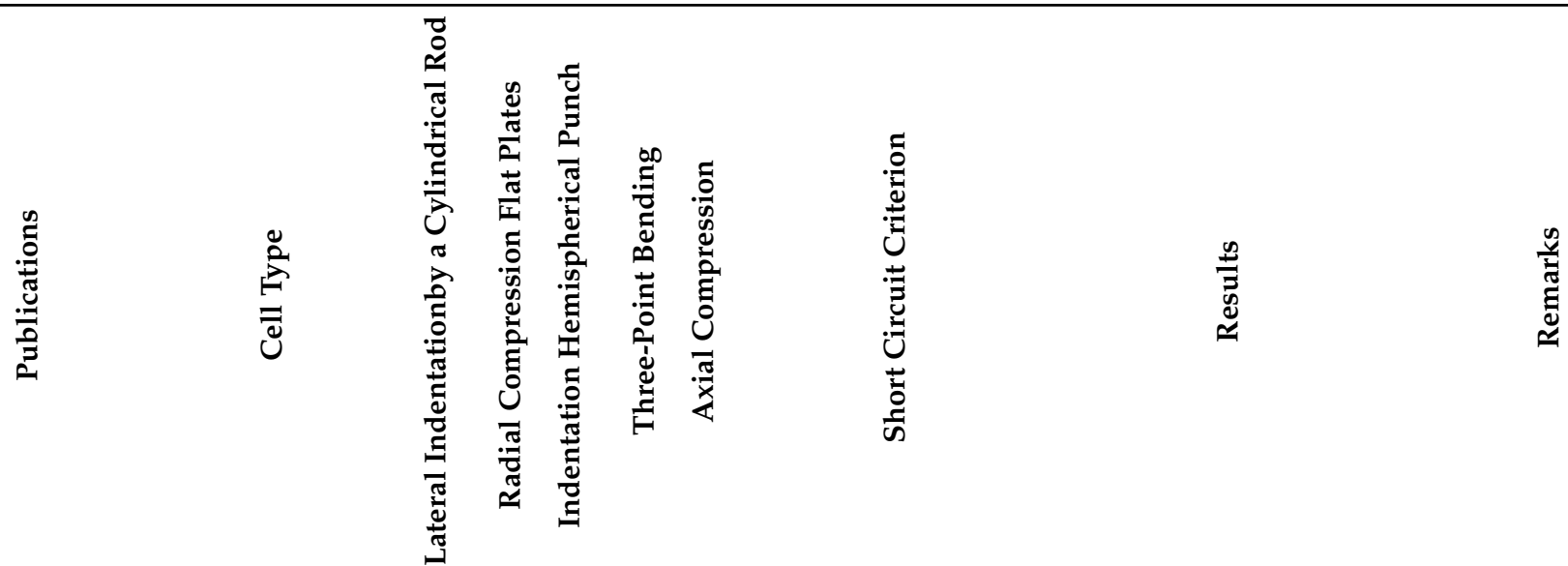

$\begin{array}{cccccccc}\text { E. Sahraei et al., } & \text { cylindrical cell } \\ 2012 \text { [3] } & 18650 & \mathrm{x} & \mathrm{x} & \mathrm{x} & \mathrm{x} & \text { force peak }\end{array}$

$\begin{array}{cccccccc}2012[3] & 18650 & x & x & x & x & \text { force peak }\end{array}$

cylindrical

nickel-cobalt

L. Greve et al., oxide (NCA) 2012 [10]

cell, (GAIA, HP

602030 NCA-45

$\mathrm{Ah} / 162 \mathrm{Wh})$

T. Wierzbicki, E. cylindrical cell

Sahraei 2013 [4] $18650 \quad x \quad x$

$$
18650
$$

$\mathrm{x}$

$\mathrm{x}$

cylindrical nickel-cobalt

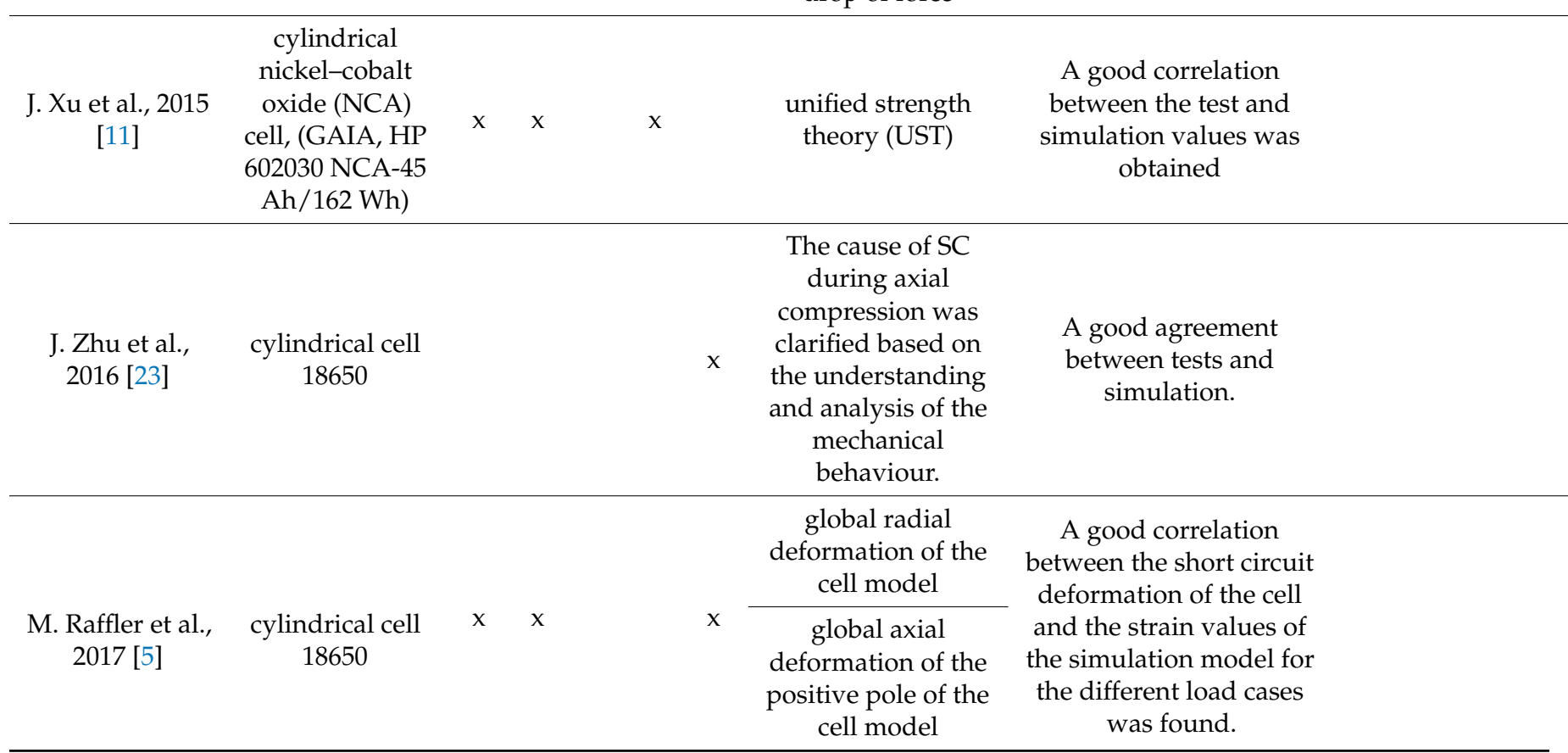

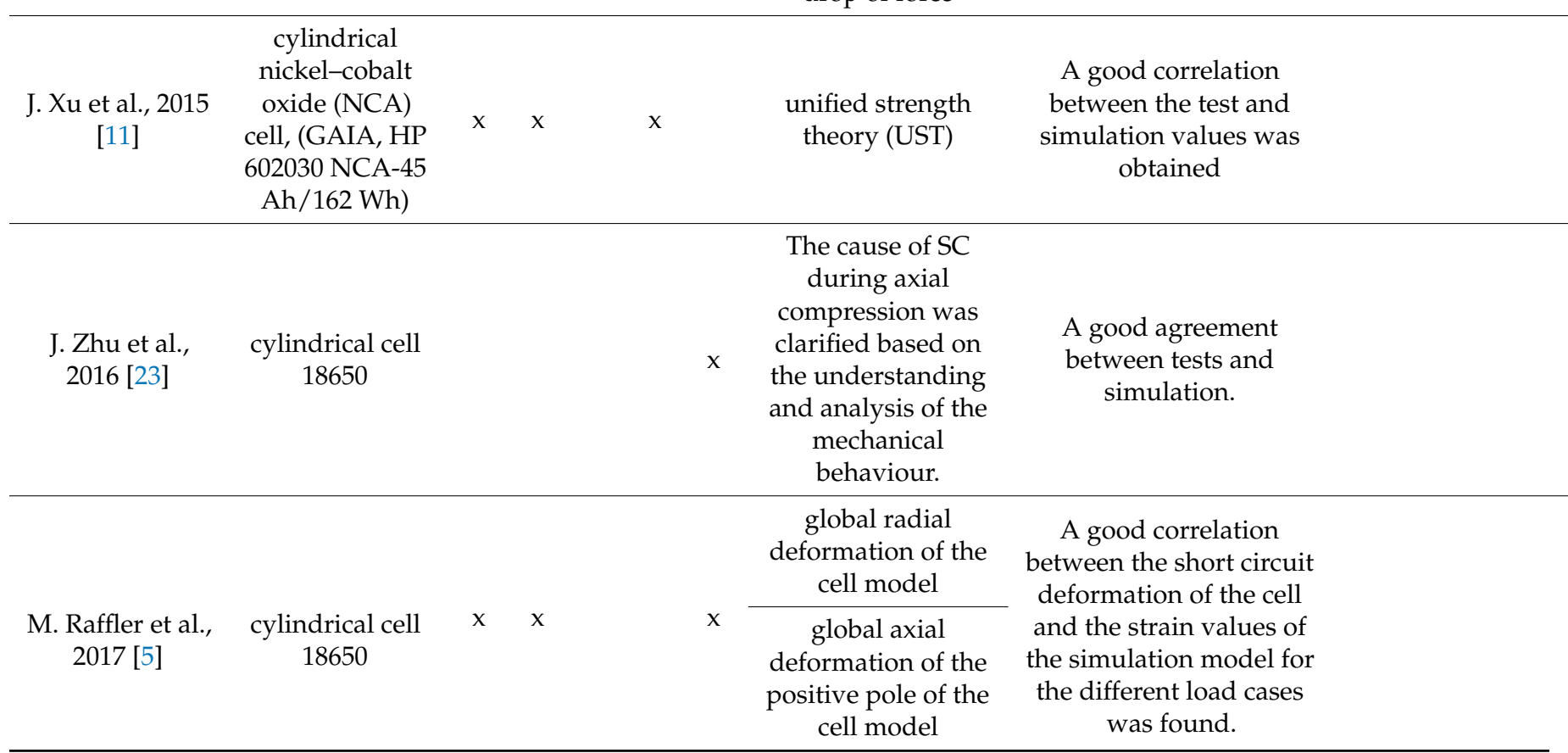

SC prediction based on the drop of voltage which coincides with the drop of force

A good correlation between the test and simulation values was obtained
For each load case the output voltage, force, displacement, and temperature versus time were recorded.
A good correlation between the test and simulation values was obtained

SC predictions were in good agreement with the experimental observations 
Table A2. Cont.

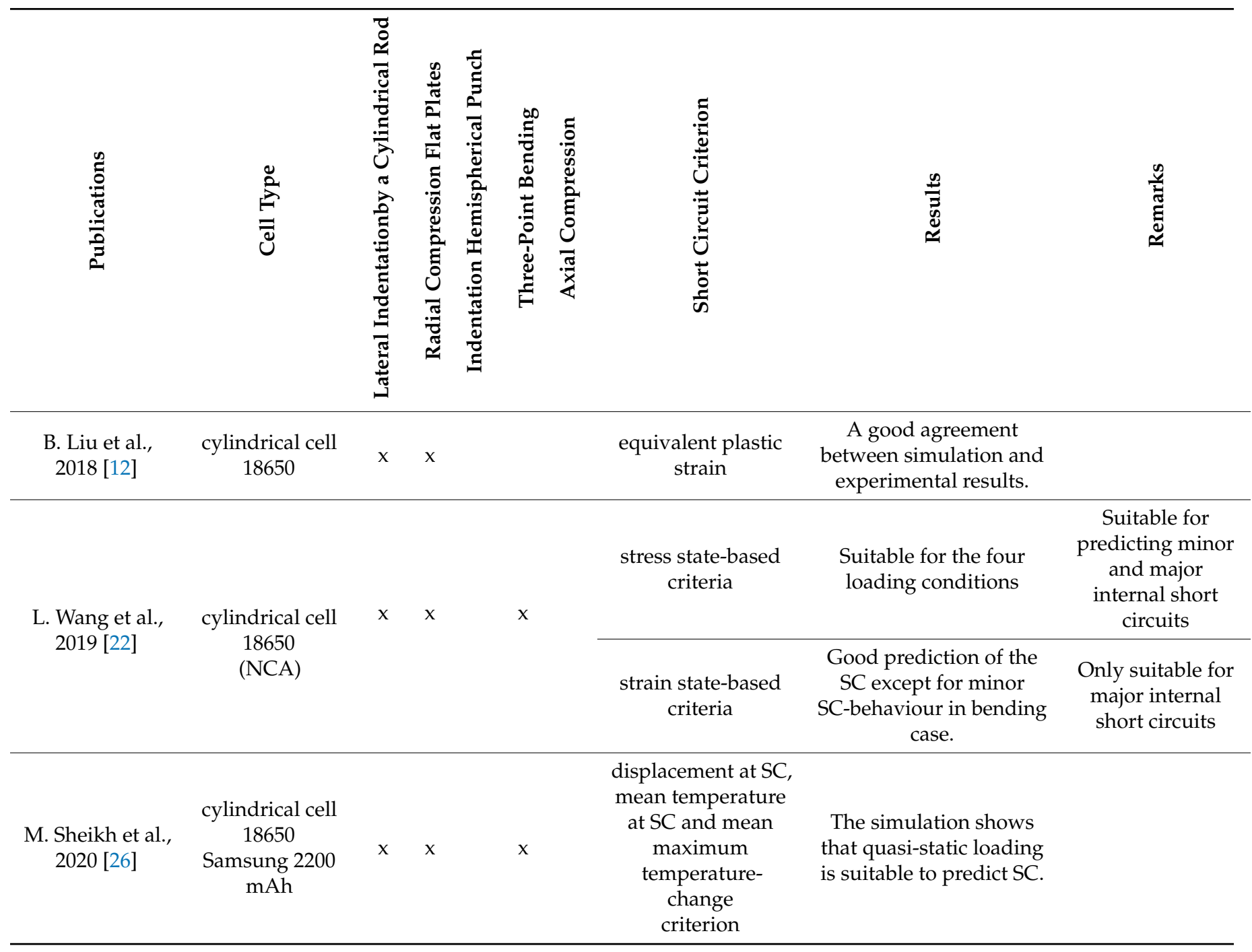

\section{Appendix B}

The following figures show additional results of the tests described in Section 2.

Figure A1 shows the test result for the cell-case tests for the axial-crush load. The results show good repeatability up to a displacement value of $10 \mathrm{~mm}$.

Figure A2 shows the test result for the cell case tests for the load radial crush. The results show good repeatability over the entire displacement interval. 


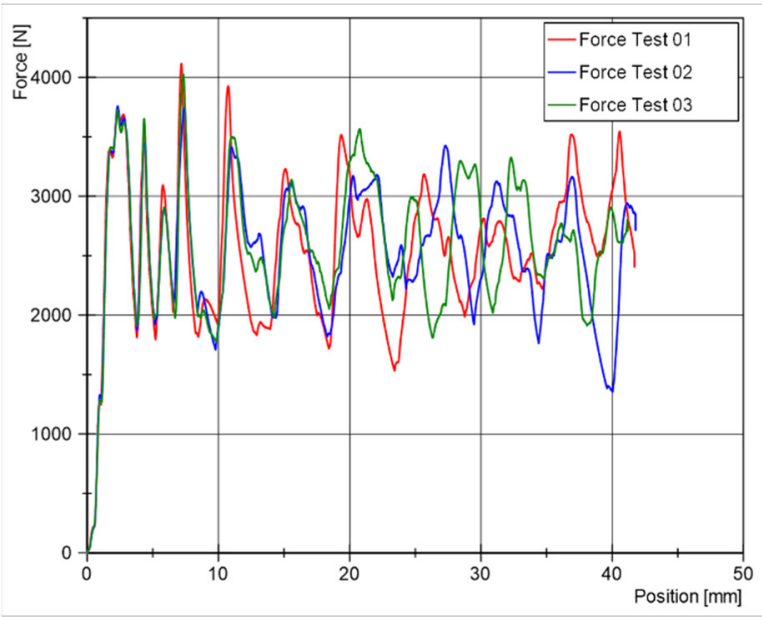

A

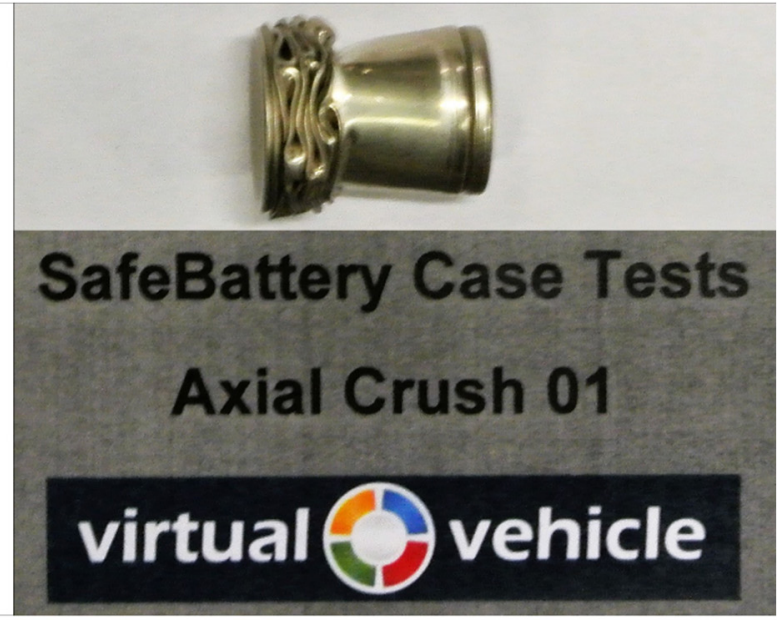

B

Figure A1. Results of the cell-case test for the load-case axial crush (A) and cell-case specimen after testing (B).

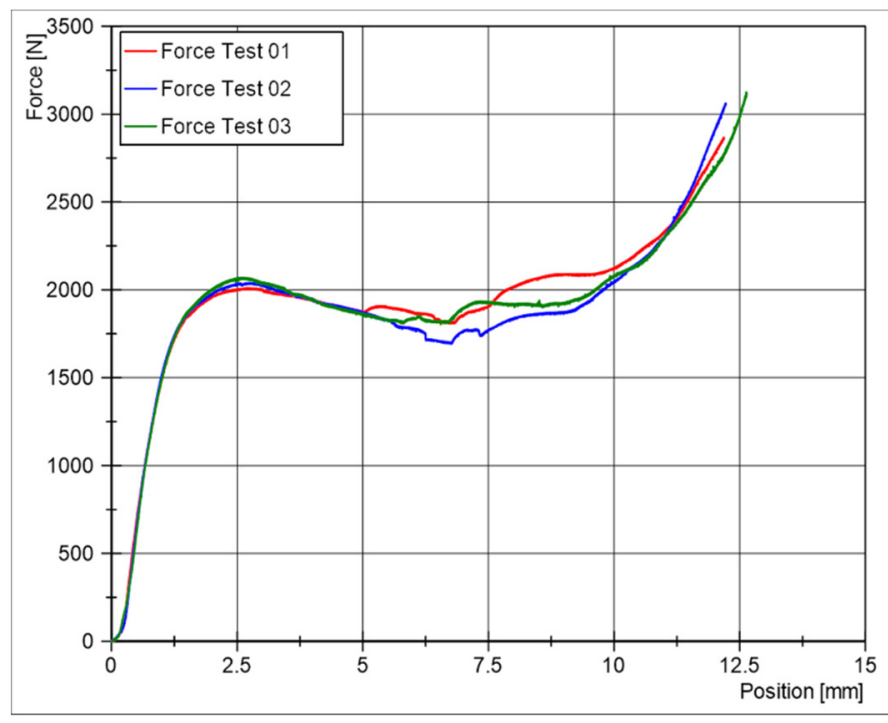

A

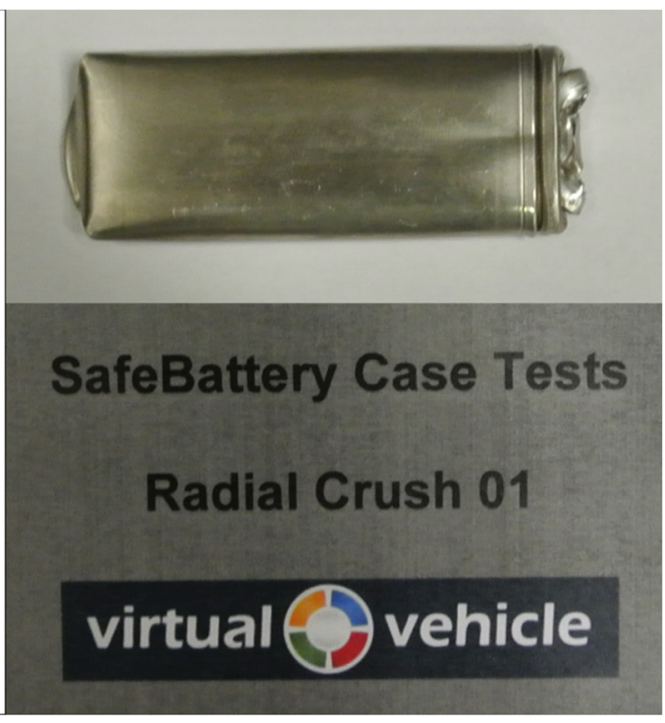

B

Figure A2. Results of the cell-case test for the load-case radial crush (A) and cell-case specimen after testing (B).

Figure A3 shows the test result for $0 \%$ SOC and for $0 \%$ SOC for the load case axial crush. The measurement of voltage was not possible due to the given test set-up (no access to cell contacts). In literature, it has been noted, that there is a correlation between the force drop and short circuit [3]. The short circuit appears at a similar level of deformation for both states of charge. 


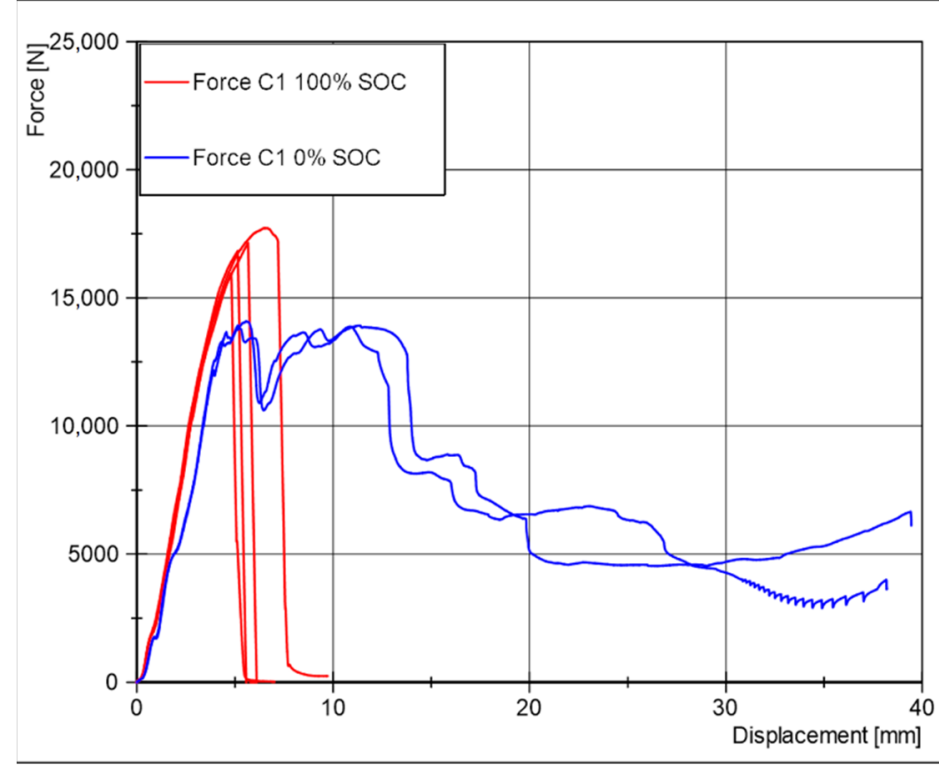

A

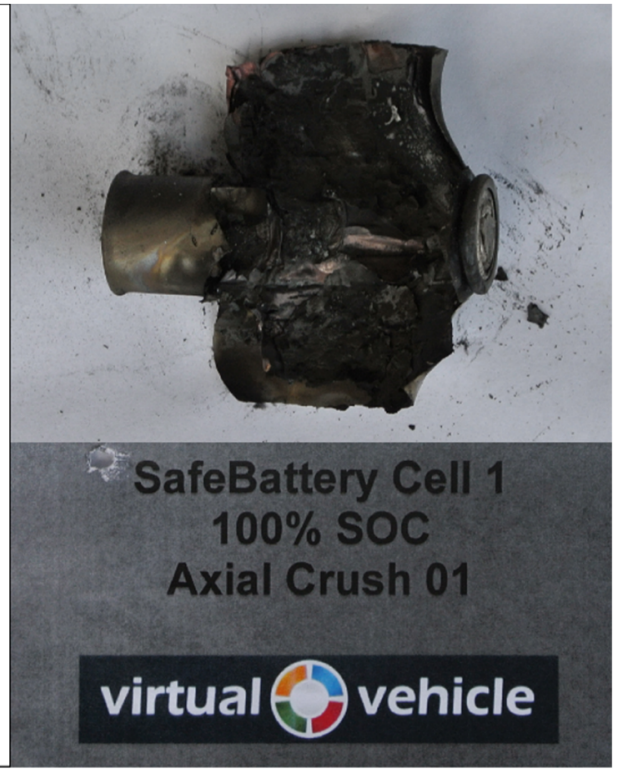

B

Figure A3. Axial crush C1 (SOC comparison) force over displacement (A) and cell specimen after testing (B).

Figure A4 shows the test result for $0 \%$ SOC and for $0 \%$ SOC for the load-case radial crush. During the radial crush tests, forces exceeded the maximum of the measurement signal. A short circuit was still reached.

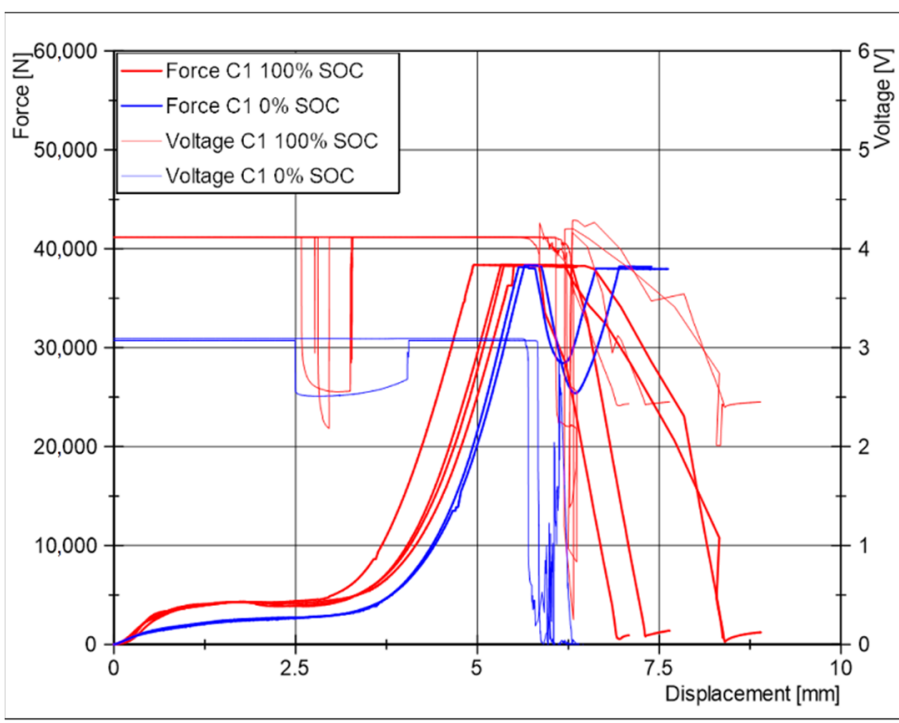

A

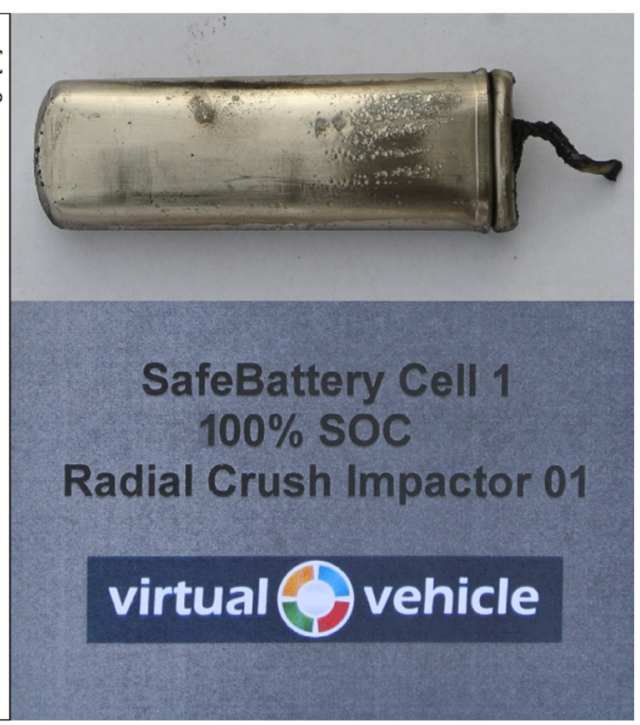

B

Figure A4. Radial crush C1 (SOC comparison) force over displacement (A) and cell specimen after testing (B).

Figure A5 shows the test result for $0 \%$ SOC and for $0 \%$ SOC for the three-point-bending load case. Possible reasons for the first drop in force are the cracking of the cell case or a defect/cracking inside the cell, without causing a short circuit. The second force drop coincides with the measured short circuit. 


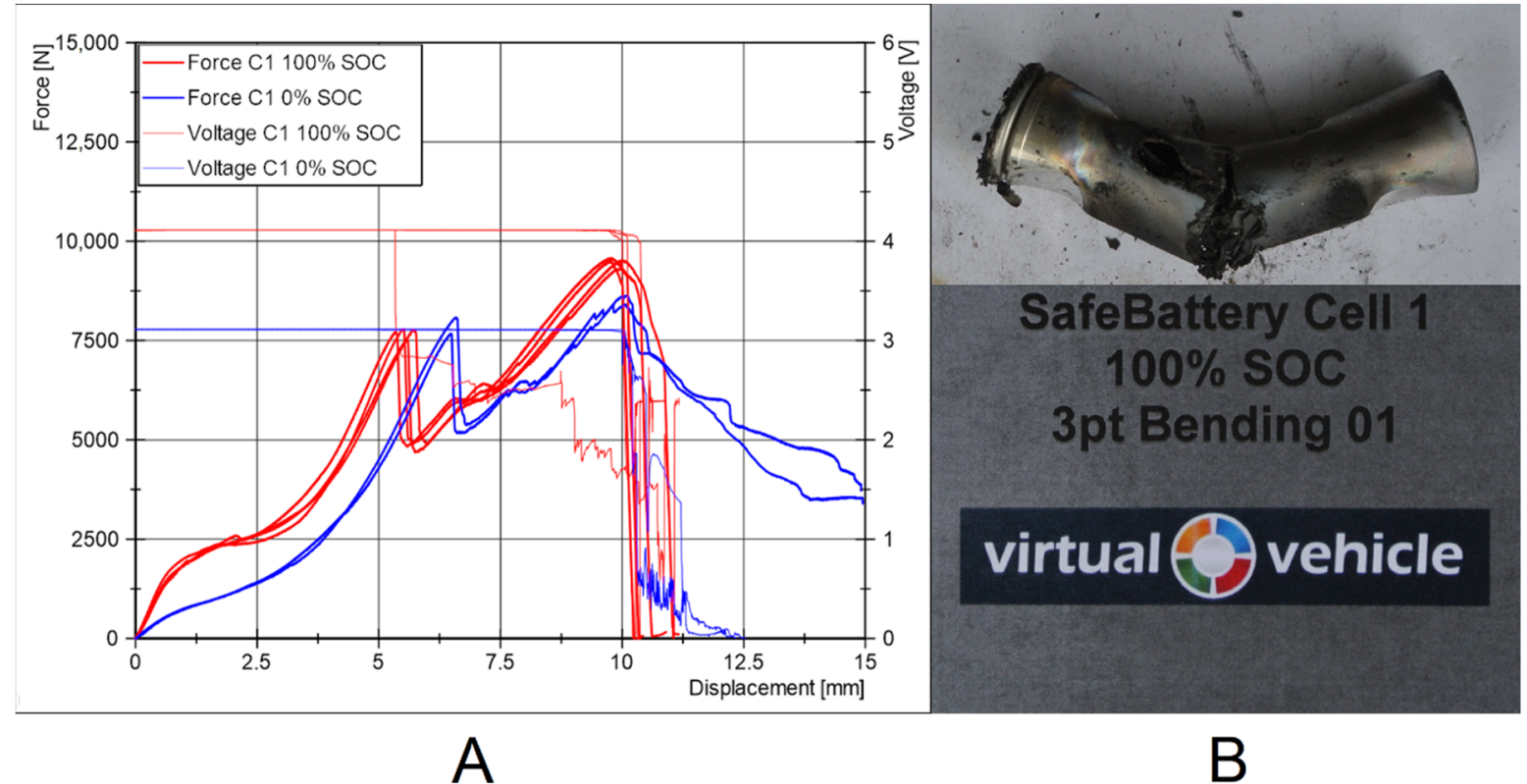

Figure A5. Three-point bending C1 (SOC comparison) force over displacement (A) and cell specimen after testing (B).

\section{References}

1. Reddy, M.V.; Mauger, A.; Julien, C.M.; Paolella, A.; Zaghib, K. Brief History of Early Lithium-Battery Development. Materials 2020, 13, 1884. [CrossRef]

2. Reddy, M.V.; Subba Rao, G.V.S.; Chowdari, B.V.R. Metal Oxides and Oxysalts as Anode Materials for Li Ion Batteries. Chem. Rev. 2013, 113, 5364-5457. [CrossRef] [PubMed]

3. Sahraei, E.; Campbell, J.; Wierzbicki, T. Modeling and short circuit detection of $18650 \mathrm{Li}$-ion cells under mechanical abuse conditions. J. Power Sources 2012, 220, 360-372. [CrossRef]

4. Wierzbicki, T.; Sahraei, E. Homogenized mechanical properties for the jellyroll of cylindrical Lithium-ion cells. J. Power Sources 2013, 241, 467-476. [CrossRef]

5. Raffler, M.; Sevarin, A.; Ellersdorfer, C.; Heindl, S.F.; Breitfuss, C.; Sinz, W. Finite element model approach of a cylindrical lithium ion battery cell with a focus on minimization of the computational effort and short circuit prediction. J. Power Sources 2017, 360, 605-617. [CrossRef]

6. Zhang, C.; Santhanagopalan, S.; Sprague, M.A.; Pesaran, A.A. A representative-sandwich model for simultaneously coupled mechanical-electrical-thermal simulation of a lithium-ion cell under quasi-static indentation tests. J. Power Sources 2015, 298, 309-321. [CrossRef]

7. Santhanagopalan, S.; Ramadass, P.; Zhang, J. Analysis of internal short-circuit in a lithium ion cell. J. Power Sources 2009, 194, 550-557. [CrossRef]

8. Keyser, M.; Kim, G.-H.; Pesaran, A.A. Numerical and experimental investigation of internal short circuits in a Li-ion cell. In DOE Vehicle Technologies Program Review; National Renewable Energy Laboratory: Golden, CO, USA, 2011.

9. Orendorff, C.J. The Role of Separators in Lithium-Ion Cell Safety. Electrochem. Soc. Interface 2012, 21, 61-65. [CrossRef]

10. Greve, L.; Fehrenbach, C. Mechanical testing and macro-mechanical finite element simulation of the deformation, fracture, and short circuit initiation of cylindrical Lithium ion battery cells. J. Power Sources 2012, 214, 377-385. [CrossRef]

11. Xu, J.; Liu, B.; Wang, L.; Shang, S. Dynamic mechanical integrity of cylindrical lithium-ion battery cell upon crushing. Eng. Fail. Anal. 2015, 53, 97-110. [CrossRef]

12. Liu, B.; Zhang, J.; Zhang, C.; Xu, J. Mechanical integrity of 18650 lithium-ion battery module: Packing density and packing mode. Eng. Fail. Anal. 2018, 91, 315-326. [CrossRef]

13. Ellersdorfer, C. Abbildung und Bewertung des Crashverhaltens von lithiumbasierten Batterien für Elektrisch Betriebene Motorräder. Ph.D. Thesis, Graz University of Technology, Graz, Austria, 2016.

14. Li, Z.; Chen, J.; Lan, F.; Li, Y. Constitutive Behavior and Mechanical Failure of Internal Configuration in Prismatic Lithium-Ion Batteries under Mechanical Loading. Energies 2021, 14, 1219. [CrossRef]

15. Ratner, A.; Beaumont, R.; Masters, I. Dynamic Mechanical Compression Impulse of Lithium-Ion Pouch Cells. Energies 2020, 13, 2105. [CrossRef]

16. Lian, J.; Koch, M.; Li, W.; Wierzbicki, T.; Zhu, J. Mechanical Deformation of Lithium-Ion Pouch Cells under in-plane Loads-Part II: Computational Modeling. J. Electrochem. Soc. 2020, 167, 090556. [CrossRef]

17. Xia, Y.; Wierzbicki, T.; Sahraei, E.; Zhang, X. Damage of cells and battery packs due to ground impact. J. Power Sources 2014, 267, 78-97. [CrossRef] 
18. Breitfuss, C.; Sinz, W.; Feist, F.; Gstrein, G.; Lichtenegger, B.; Knauder, C.; Ellersdorfer, C.; Moser, J.; Steffan, H.; Stadler, M.; et al. A 'Microscopic' Structural Mechanics FE Model of a Lithium-Ion Pouch Cell for Quasi-Static Load Cases. SAE Int. J. Passeng. Cars-Mech. Syst. 2013, 6, 1044-1054. [CrossRef]

19. Smith, M. ABAQUS/Standard User's Manual, Version 6.9; Dassault Systèmes Simulia Corp.: Providence, RI, USA, 2009.

20. LS-Dyna Volume II Materials_LS-DYNA_Manual_Volume_II_R9.0.pdf. Available online: https:/ /ftp.lstc.com/anonymous / outgoing/jday/manuals/LS-DYNA_Manual_Volume_II_R9.0.pdf (accessed on 16 November 2021).

21. Xu, J.; Liu, B.; Wang, X.; Hu, D. Computational model of 18650 lithium-ion battery with coupled strain rate and SOC dependencies. Appl. Energy 2016, 172, 180-189. [CrossRef]

22. Wang, L.; Yin, S.; Xu, J. A detailed computational model for cylindrical lithium-ion batteries under mechanical loading: From cell deformation to short-circuit onset. J. Power Sources 2019, 413, 284-292. [CrossRef]

23. Zhu, J.; Zhang, X.; Sahraei, E.; Wierzbicki, T. Deformation and failure mechanisms of 18650 battery cells under axial compression. J. Power Sources 2016, 336, 332-340. [CrossRef]

24. Tang, L.; Zhang, J.; Cheng, P. Homogenized modeling methodology for 18650 lithium-ion battery module under large deformation. PLoS ONE 2017, 12, e0181882. [CrossRef]

25. Wang, W.; Yang, S.; Lin, C.; Li, Y. Mechanical and electrical response of cylindrical Lithium-ion cells at various State of Charge. Energy Procedia 2018, 145, 128-132. [CrossRef]

26. Sheikh, M.; Elmarakbi, A.; Rehman, S. A combined experimental and simulation approach for short circuit prediction of 18650 lithium-ion battery under mechanical abuse conditions. J. Energy Storage 2020, 32, 101833. [CrossRef] 